\title{
Sensitivity studies for a space-based methane lidar mission
}

\author{
C. Kiemle, M. Quatrevalet, G. Ehret, A. Amediek, A. Fix, and M. Wirth \\ Deutsches Zentrum für Luft- und Raumfahrt (DLR), Institut für Physik der Atmosphäre, 82234 Oberpfaffenhofen, Germany
}

Received: 23 May 2011 - Published in Atmos. Meas. Tech. Discuss.: 9 June 2011

Revised: 15 September 2011 - Accepted: 8 October 2011 - Published: 18 October 2011

\begin{abstract}
Methane is the third most important greenhouse gas in the atmosphere after water vapour and carbon dioxide. A major handicap to quantify the emissions at the Earth's surface in order to better understand biosphere-atmosphere exchange processes and potential climate feedbacks is the lack of accurate and global observations of methane. Space-based integrated path differential absorption (IPDA) lidar has potential to fill this gap, and a Methane Remote Lidar Mission (MERLIN) on a small satellite in polar orbit was proposed by DLR and CNES in the frame of a German-French climate monitoring initiative. System simulations are used to identify key performance parameters and to find an advantageous instrument configuration, given the environmental, technological, and budget constraints. The sensitivity studies use representative averages of the atmospheric and surface state to estimate the measurement precision, i.e. the random uncertainty due to instrument noise. Key performance parameters for MERLIN are average laser power, telescope size, orbit height, surface reflectance, and detector noise. A modestsize lidar instrument with $0.45 \mathrm{~W}$ average laser power and $0.55 \mathrm{~m}$ telescope diameter on a $506 \mathrm{~km}$ orbit could provide $50-\mathrm{km}$ averaged methane column measurement along the sub-satellite track with a precision of about $1 \%$ over vegetation. The use of a methane absorption trough at $1.65 \mu \mathrm{m}$ improves the near-surface measurement sensitivity and vastly relaxes the wavelength stability requirement that was identified as one of the major technological risks in the pre-phase A studies for A-SCOPE, a space-based IPDA lidar for carbon dioxide at the European Space Agency. Minimal humidity and temperature sensitivity at this wavelength position will enable accurate measurements in tropical wetlands, key
\end{abstract}

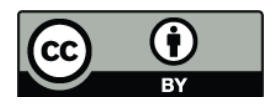

Correspondence to: C. Kiemle (christoph.kiemle@dlr.de) regions with largely uncertain methane emissions. In contrast to actual passive remote sensors, measurements in Polar Regions will be possible and biases due to aerosol layers and thin ice clouds will be minimised.

\section{Introduction}

Despite its comparatively low atmospheric abundance, methane is the third most important greenhouse gas in the atmosphere after water vapour and carbon dioxide, and after carbon dioxide, the second most important greenhouse gas directly augmented by human activities. It accounts for $18 \%$ of the radiative forcing by the major long-lived anthropogenic greenhouse gases. Since pre-industrial times the methane mixing ratio has increased by a factor of 2.5 to actually $1.77 \mathrm{ppmv}$ (parts per million by volume). While carbon dioxide is about 220 times more abundant, its radiative forcing is only a factor of 3.5 higher (IPCC, Forster et al., 2007). On a per-unit-volume basis, methane is consequently 63 times more effective than carbon dioxide in absorbing long-wave radiation, because the methane absorption lines in the long-wave spectrum are less saturated and have less overlap with water vapour lines. Today, natural and agricultural sources of methane dominate, yet they are very difficult to quantify. Since 1850 its strong atmospheric concentration increase was mainly from anthropogenic sources: rice agriculture, biomass burning, ruminant animals, and fossil fuel mining. However, these sources could be dwarfed by the release of huge amounts of methane from melting permafrost in the arctic or from methane hydrates buried in ocean sediment. Milkov (2004) put the global estimate of methane hydrates at 500-2500 Gt of carbon; for reference the total proven fossil fuel reserves are about $750 \mathrm{Gt}$ carbon. Today, hydrates and

Published by Copernicus Publications on behalf of the European Geosciences Union. 
permafrost are only a small contribution to the methane budget, but we need to be able to monitor these potential methane source regions should they awaken. In the past 20 years the increase of atmospheric methane has almost stopped, for yet unknown reasons. Since its main sink, tropospheric $\mathrm{OH}$, has negligible long-term change, this implies a stabilisation of the emissions (Forster et al., 2007). However, a flare-up of the methane concentration was observed recently (Schneising et al., 2011) and concern by climate feedback effects in a warmer atmosphere has risen (Heimann, 2010; Davy et al., 2010).

A major handicap to better understand the underlying processes and to quantify the emissions is the lack of accurate global observations of atmospheric methane. Ground-based in-situ measurements are insufficient because the existing observational network is too coarse (Villani et al., 2010), because source regions of key importance to the global carbon cycle (Arctic permafrost, Boreal forests, Tropical wetlands) are difficult to access and hence underrepresented or not sampled at all, and because the measurements are biased by local circulations and fluxes (Gerbig et al., 2009). Ground-based remote sensing by Fourier transform spectrometry (FTS; Petersen et al., 2010) yields integrated column measurements along the line of sight, with the advantage that the methane columns are to first order conserved when the height of the mixing layer above methane sources changes. On the other hand, surface or tower in-situ measurements within the mixed layer are sensitive to mixing height changes (Gerbig et al., 2009). Spectrometer on low earth orbit satellites such as SCIAMACHY onboard ENVISAT (Schneising et al., 2011) and TANSO onboard GOSAT (Morino et al., 2011) observe solar light reflected from the earth's surface and atmosphere to retrieve trace gas concentrations. However, they poorly cover the above mentioned critical source regions and are blind in high-latitude dark regions (Morino et al., 2011). In addition, passive remote sensing suffers from low measurement sensitivity in the lower troposphere near the Earth's surface where the methane sources reside. Finally, undetected aerosol layers or thin ice clouds produce systematic measurement errors of unknown magnitude, because of the complexity of the retrieval algorithms and the limited availability of independent measurements for validation (Petersen et al., 2010).

Space-based active remote sensing using differential absorption lidar is particularly sensitive near the surface, has insignificant aerosol biases, can measure in dark Polar Regions, and offers high and quantifiable accuracy and precision. For carbon dioxide, ESA and NASA recently proposed the lidar missions A-SCOPE (Advanced Space Carbon and Climate Observation of Planet Earth; Ingmann et al., 2008) and ASCENDS (Active Sensing of $\mathrm{CO}_{2}$ Emissions over Nights, Days and Seasons; Kawa et al., 2010), respectively. They intend to use integrated-path differential absorption (IPDA) lidar systems to derive the atmospheric carbon dioxide columns from laser light reflections off the earth's surface. A series of recent studies shows the potential of this new technology: Installed on a low Polar orbit satellite, lidar overcomes the difficulties of ground-based and passive space-based observation systems by providing column measurements with an accuracy of better than $1 \%$, a precision of around $1 \%$, and global coverage between $83^{\circ} \mathrm{S}$ and $83^{\circ} \mathrm{N}$, independent of aerosol load, season, or daylight (Dufour and Bréon, 2003; Ehret and Kiemle, 2005; Bréon et al., 2008; Ehret et al., 2008; Amediek et al., 2009; Kaminski et al., 2010; Kawa et al., 2010; Hungershoefer et al., 2010). According to common practice we relate the instrument's accuracy to the systematic uncertainty or bias of the measurement, and the precision to the random uncertainty from instrument noise and random uncertainties in the auxiliary parameters used in the retrieval, both with one-sigma bounds, assuming Gaussian error distributions. The last three references demonstrate that a high benefit from such accurate measurements can be expected when the data are supplied to inverse numerical models that infer methane fluxes from the globally observed spatio-temporal concentration gradients. They conclude that space-based lidar will provide strong constraints on the inversion calculations and reduce the surface flux uncertainties because the lidar provides additional information beyond today's ground-based network and space-based passive instruments.

For methane the observational requirements are considerably relaxed, since anthropogenic methane sources make up $\sim 60 \%$ of the total emissions (Heimann, 2010), and measurement accuracy and precision need not be as rigorous as for carbon dioxide where the anthropogenic contributions are blurred by natural variability. The observational requirements have been established in the frame of a comprehensive study (Ehret and Kiemle, 2005) and basically comprise a methane column measurement precision of between 0.6$2.0 \%$ at a spatial measurement resolution of $50 \mathrm{~km}$. Furthermore, a major spectroscopic advantage over carbon dioxide is the existence of particular absorption line multiplets of methane. As described in this paper, this can be favourably used to drastically relax the accuracy requirements of the laser transmitter's frequency stability and of the satellite's along-track pointing. This entails reduced instrument cost, size and risk which is beneficial for the deployment of new space technology such as IPDA lidar.

In the frame of a German-French climate monitoring initiative, a "Methane Remote Lidar Mission" (MERLIN) on a small satellite in low Polar orbit was therefore proposed by DLR, responsible for the instrument, and CNES, responsible for the platform (Ehret et al., 2010). The basic objectives are (1) to better quantify methane emissions, (2) to improve the distinction between natural and anthropogenic sources, and (3) to advance our understanding of this essential branch of the carbon cycle. This paper presents a comprehensive analysis of the foreseen performance of MERLIN on the basis of the lidar system simulations elaborated in Ehret et al. (2008). While that paper more generally described the basic IPDA 
issues related to the measurement accuracy (systematic uncertainties), the present study focuses on the selection of appropriate methane absorption lines, and on the expected measurements' precision (random uncertainties). In the next section, IPDA is briefly introduced. Section 3 explains the selection of favourable methane absorption lines using line-byline radiative transfer calculations under various atmospheric conditions. Section 4 introduces the simulation model and the MERLIN baseline system configuration, and Sect. 5 discusses the performance analysis trade-offs and results. Since we felt it useful to detail the IPDA equations and error assessments without complicating the core messages of the paper, we put them into an Appendix.

\section{Integrated-path differential absorption lidar}

IPDA lidar uses the laser light scattered back from a surface ("hard target") to obtain measurements of the column content of a specific atmospheric trace gas between lidar and target. Figure 1 shows the measurement geometry of a nadirviewing satellite lidar with the measurements aligned along the sub-satellite track. Differential absorption uses the difference in atmospheric transmission between a laser emission with a wavelength placed at or near the centre of a methane absorption line, denoted on-line, and a reference off-line wavelength with significantly less absorption. Close collocation of the on- and off-line wavelength positions is required to avoid biases by the wavelength-dependency of aerosols, clouds, and the surface. In addition, close spatial beam collocation is mandatory to circumvent biases by the variability of atmospheric and surface scatter. Amediek et al. (2009) used airborne lidar measurements to assess the error induced by partial overlap of the on- and offline footprints in the context of varying surface reflectance. When adapting their approach to the measurement geometry displayed in Fig. 1, the average error on the methane column measurement due to an onand offline footprint shift of $10 \mathrm{~m}$ amounts to $\sim 0.15 \%$ over land surfaces, which is small but not negligible.

Assuming a pulsed lidar system with full overlap between the on- and off-line spots on the scattering surface for the sake of simplicity, the optical power $P$ of the backscattered laser photons incident on the receiving telescope area and focused onto the sensitive area of the detector is given by the following "hard target" lidar equation:

$$
\begin{aligned}
P_{\mathrm{on} / \mathrm{off}} & =\rho \cdot \eta \cdot A \cdot R^{-2} \cdot E_{\mathrm{on} / \mathrm{off}} \cdot \Delta t_{\mathrm{eff}}^{-1} \\
& \cdot \exp \left(-2 \cdot\left(\mathrm{OD}_{0}+\sum_{g} \mathrm{OD}_{g, \text { on } / \mathrm{off}}\right)\right) .
\end{aligned}
$$

Here $\rho$ represents the surface reflectance in $\mathrm{sr}^{-1}$, defined such that for a Lambertian surface the albedo would be $\rho \cdot \pi$. The factor $\eta$ is the receiver's total optical efficiency, $A$ the telescope area, $R$ the distance to the surface, $E_{\text {on/off }}$

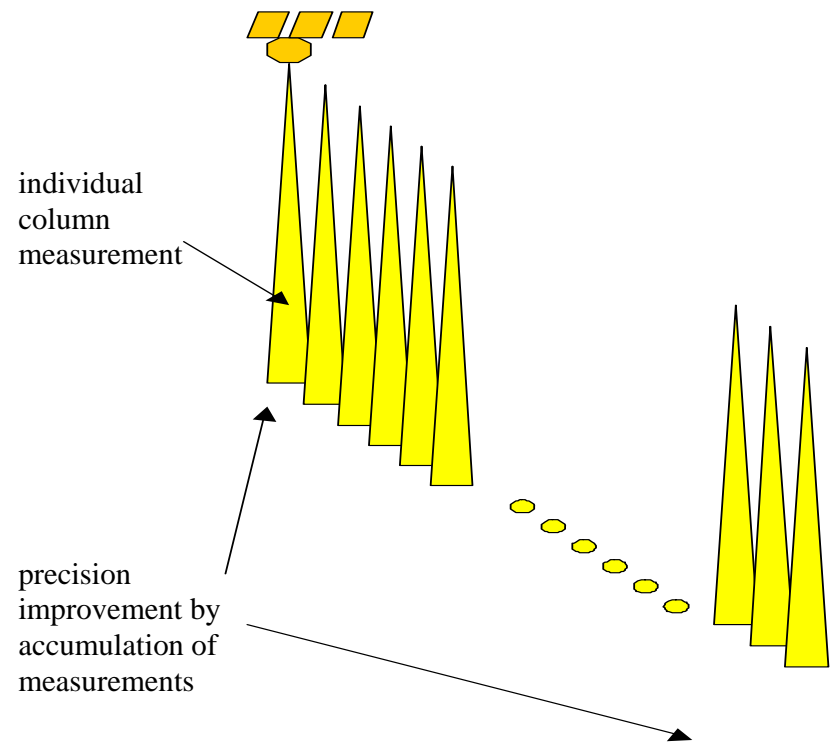

Fig. 1. Measurement alignment for a space-based nadir-viewing methane lidar. With the baseline lidar and platform parameters from Table 2, individual column measurements have a surface spot diameter of $135 \mathrm{~m}$ and a precision of $10 \%$. The columns are separated by $280 \mathrm{~m}$ and hence do not overlap. All 177 measurements accumulated within a length of $50 \mathrm{~km}$ have a precision of $0.8 \%$.

the on- or offline laser pulse energy, and $\Delta t_{\text {eff }}$ the effective laser pulse length, explained in Sect. 4. $\mathrm{OD}_{0}$ is the optical depth due to atmospheric extinction by air molecules, aerosols, and clouds, while $\mathrm{OD}_{g \text {, on/off }}$ are the total column optical depths by molecular absorption of the trace gas $g$ between instrument and scattering surface at the on- or off-line wavelengths. The logarithm of the ratio of $P_{\text {off }}$ and $P_{\text {on }}$, normalised by the associated ratio of pulse energies that also have to be measured for each lidar pulse, yields the Differential Atmospheric Optical Depth (DAOD) for the selected pair of wavelengths:

$\mathrm{DAOD}=\sum_{g} \mathrm{DAOD}_{g}=\frac{1}{2} \cdot \ln \left(\frac{P_{\mathrm{off}} \cdot E_{\mathrm{on}}}{P_{\mathrm{on}} \cdot E_{\mathrm{off}}}\right)$,

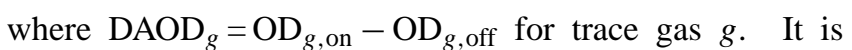
possible to find a pair of on- and off-line wavelengths for which only the trace gas of interest, here methane, contributes to this spectral difference. Under these conditions, $\mathrm{DAOD}=\mathrm{DAOD}_{\mathrm{CH}_{4}}$. As explained in the Appendix, $\mathrm{DAOD}_{\mathrm{CH}_{4}}$ is proportional to a weighted average of the methane dry-air volume mixing ratio along the probed column, $\mathrm{XCH}_{4}$, which is the quantity of scientific interest:

$$
X \mathrm{CH}_{4}=\frac{\mathrm{DAOD}_{\mathrm{CH}_{4}}}{\int_{p=0}^{p_{\mathrm{SFC}}} \operatorname{WF}_{\mathrm{CH}_{4}}(p) \cdot \mathrm{d} p} .
$$

The denominator is the integral of the so-called weighting function (WF) along the probed column, determined solely 


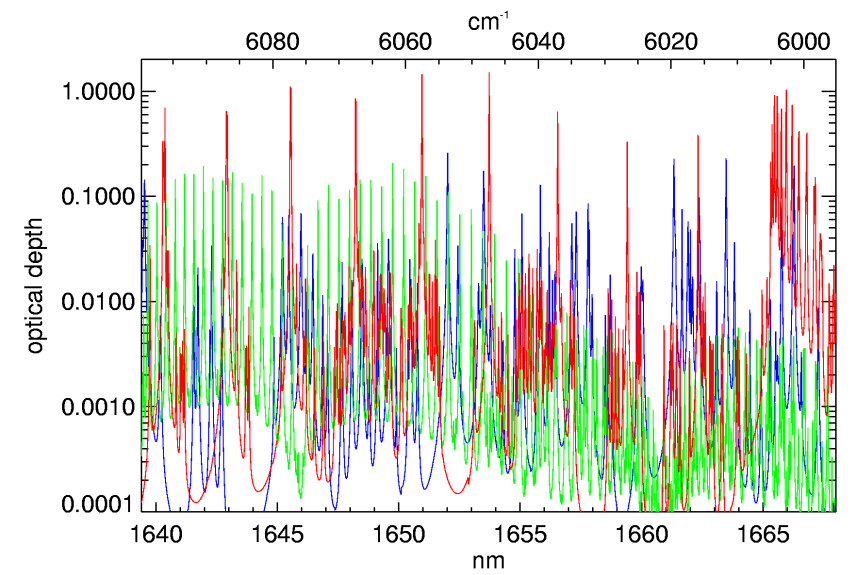

Fig. 2. Optical depth of the vertical total atmospheric column of water vapour (blue), carbon dioxide (green) and methane (red) absorption lines under standard atmospheric conditions, as function of wavelength and wavenumber (top axis), from HITRAN 2008 data.

by atmospheric parameters that can be obtained from NWP model results. Assuming Gaussian statistics and using the notation $\delta Y$ for the 1- $\sigma$ random uncertainty on variable $Y$, the total relative uncertainty on $\mathrm{XCH}_{4}$ is given by differentiating Eq. (3):

$$
\frac{\delta X \mathrm{CH}_{4}}{X \mathrm{CH}_{4}}=\sqrt{\left(\frac{\delta \mathrm{DAOD}_{\mathrm{CH}_{4}}}{\mathrm{DAOD}_{\mathrm{CH}_{4}}}\right)^{2}+\left(\frac{\delta\left(\int_{p=0}^{p \mathrm{SFC}} \mathrm{WF}_{\mathrm{CH}_{4}}(p) \cdot \mathrm{d} p\right)}{\int_{p=0}^{p \mathrm{SFC}} \mathrm{WF}_{\mathrm{CH}_{4}}(p) \cdot \mathrm{d} p}\right)^{2}}
$$

In the next section the second term in the sum of Eq. (4) is quantified, and the results are used to select a suitable on/off-line wavelength pair. Section 4 , on the other hand, assesses the magnitude of the first term.

\section{Methane absorption line selection}

The selection of appropriate absorption lines is ruled by a series of constraints: Particularly, overlaps by other absorbing trace gases have to be avoided, and temperature-insensitive absorption lines with suitable strength have to be selected. If the line is too weak, the differential absorption is weak and the signal-to-noise ratio (SNR) becomes poor. On the other hand, too strong absorption lowers the transmission such that the return signal becomes too weak. This differential absorption lidar "dilemma" (Bruneau et al., 2006) gives an optimum DAOD of $\sim 0.5$ for the MERLIN baseline presented in the next section. Methane absorption bands, detector efficiency and eye safety considerations determine the overall wavelength range. In the short-wave infrared where eye safety for a zenith-viewing observer is less critical, methane lines with appropriate strength are essentially found in two water

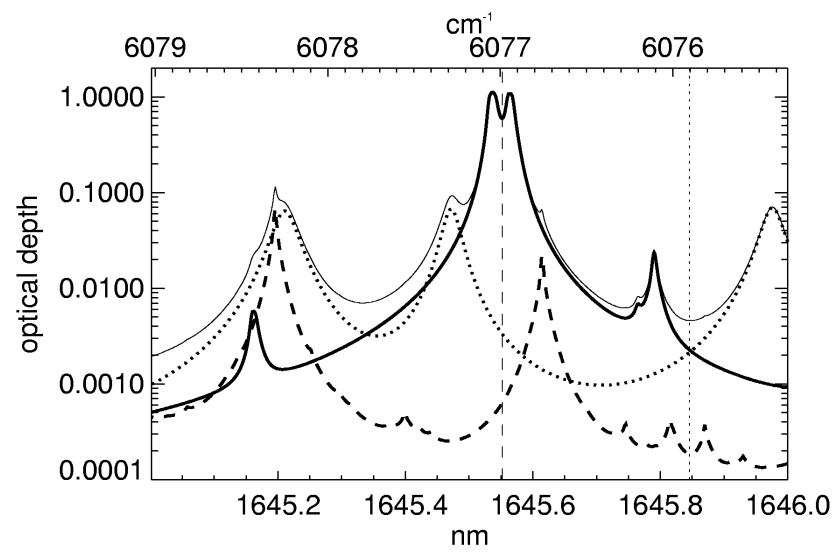

Fig. 3. Optical depth of the total vertical atmospheric column for option 2 of Table 1 under standard atmospheric conditions of water vapour (dotted), carbon dioxide (dashed) and methane (solid) absorption lines. The thin solid line is the total optical depth of all three trace gases. The online (offline) wavelength position selected for the baseline system configuration is indicated by the thin vertical dashed (dotted) line.

vapour transmission windows around 1.6 and $2.3 \mu \mathrm{m}$. Detector performance is significantly better at $1.6 \mu \mathrm{m}$ where lownoise InGaAs avalanche photodiodes (APD) with high quantum efficiency are available. Figure 2 gives an overview of this $2 v_{3}$ methane absorption band, where weak carbon dioxide lines are found to populate more the left hand side and water vapour lines more the right hand side. Several methane absorption features with appropriate optical depth emerge. A closer look, as provided by Fig. 3, reveals that some of them appear as pairs of closely-packed line multiplets with a local minimum of absorption in between, hereafter referred to as "absorption trough" or "trough".

If the distance between the multiplets is such that the optical depth in the trough is close to the optimum value $(0.5)$, the spectral position in the centre of the trough fulfils several major selection criteria for a suitable on-line IPDA sounding wavelength. In particular, it is in the wing of all the neighbouring lines, giving enhanced sensitivity to the measurements in the lower troposphere, as discussed below and in Ehret et al. (2008). In addition, the trough position provides a decisive advantage over a single, isolated absorption line: while the large derivative of optical depth with respect to frequency (or wavelength) in the wing of such a line makes the measurement very sensitive to any unknown frequency instability of the emitted pulses, the local minimum of optical depth in the trough corresponds to a zero crossing of the derivative, with an associated region of very low sensitivity to frequency shifts, as Fig. 3 illustrates. A more quantitative analysis reveals that when positioning the online within $\pm 100 \mathrm{MHz}$ around the minimum of the trough, the derivative of optical depth with respect to frequency remains a factor fifty to hundred lower than outside the trough in the steep 
Table 1. Suitable line multiplets in the $2 v_{3}$ methane absorption band for space IPDA lidar applications, with proposed online/offline lidar wavelength pairs and uncertainties due to atmospheric temperature, humidity, and surface pressure uncertainties (for details see Appendix). Option 2 at $1645 \mathrm{~nm}$ is selected due to its outstanding sensitivity in the lower troposphere.

\begin{tabular}{|c|c|c|c|c|}
\hline Option & 1 & 2 & 3 & 4 \\
\hline Lower rotational level $J^{\prime \prime}$ & R7 & R6 & R5 & Q6 \\
\hline On-line wavelength (nm) & 1642.9093 & 1645.5518 & 1648.2279 & 1665.9562 \\
\hline On-line wavenumber $\left(\mathrm{cm}^{-1}\right)$ & 6086.7632 & 6076.9889 & 6067.1220 & 6002.5588 \\
\hline Off-line wavenumber $\left(\mathrm{cm}^{-1}\right)$ & 6085.0000 & 6075.8960 & 6068.5250 & 6004.5000 \\
\hline Separation between on- and off-line (nm) & 0.48 & 0.30 & 0.38 & 0.54 \\
\hline DAOD, one-way, total atmosphere & 0.52 & 0.53 & 0.60 & 0.54 \\
\hline Weighting function figure of merit (Fig. 4) & 0.91 & 1.23 & 0.88 & 0.98 \\
\hline \multicolumn{5}{|c|}{ Uncertainties on $\mathrm{XCH}_{4}$ from geophysical parameter uncertainties: } \\
\hline Temperature profile (ECMWF) $(\%$ ) & $0.20-0.49$ & $0.20-0.34$ & $0.25-0.34$ & $0.10-0.19$ \\
\hline Humidity profile (ECMWF) (\%o) & $0.28-0.30$ & $0.08-0.13$ & $0.25-0.26$ & $0.12-0.18$ \\
\hline Surface pressure $(1 \mathrm{hPa})(\% \circ)$ & 0.99 & 0.98 & 0.97 & 0.97 \\
\hline $\begin{array}{l}\text { Total rms uncertainty on } \mathrm{XCH}_{4} \\
\text { from geophysical parameters }(\% \text { o) }\end{array}$ & $1.18-1.27$ & $1.14-1.18$ & $1.17-1.19$ & $1.12-1.14$ \\
\hline
\end{tabular}

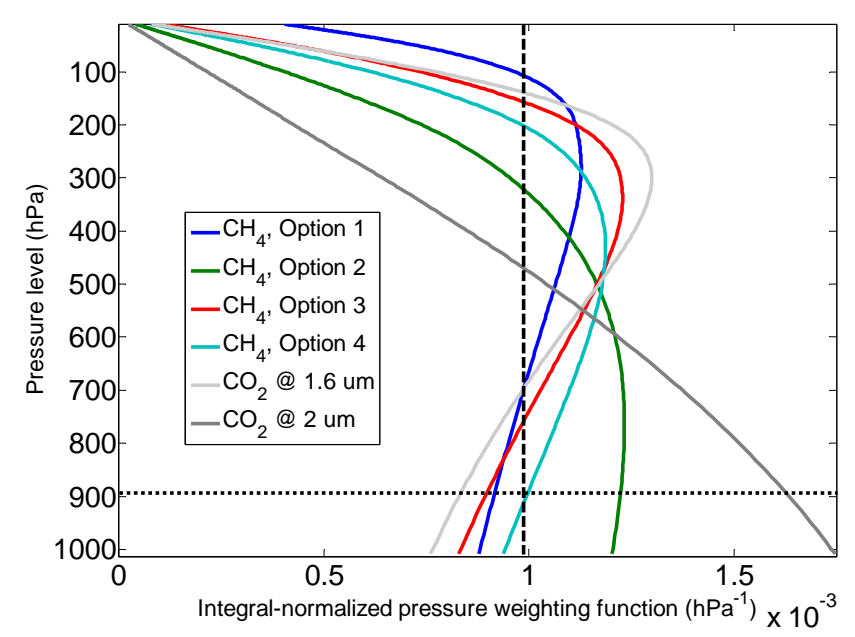

Fig. 4. Integral-normalized pressure weighting functions of IPDA lidar for all four suitable methane absorption trough positions at $1.6 \mu \mathrm{m}$ listed in Table 1 , and for carbon dioxide line wing positions at 1.6 and $2 \mu \mathrm{m}$ for comparison. Also shown is a hypothetical uniform weighting function (normalized; vertical dashed line) and the assumed top of the lowest 1-km layer (dotted horizontal line at $894 \mathrm{hPa}$ ) used to define the figure of merit of the weighting function. Option 2 at $1645 \mathrm{~nm}$ is selected due to its outstanding sensitivity in the lower troposphere.

flank of a line. Consequently, in contrast to using the wing of a single line, as is the case for $\mathrm{CO}_{2}$ where no such troughs exist, the frequency stability requirement can be reduced by a similar factor, which is of great benefit to the laser design and to the platform along-track nadir pointing offset that introduces a Doppler shift in the frequency of the received pulses.
We used line-by-line radiative transfer calculations under standard atmospheric conditions with the HITRAN 2008 database (Rothman et al., 2009), including recent spectroscopic characterizations of methane precisely in this $2 v_{3}$ absorption band (Frankenberg et al., 2008), to identify the best suitable methane trough, following a formulation documented in the Appendix. In total, we find four methane absorption troughs with suitable optical depth, low temperature dependency, and without significant interference by other trace gases. Figure 4 displays their integralnormalized weighting functions. While options 1,3 and 4 have only slightly better low-tropospheric weighting functions than a $\mathrm{CO}_{2}$ single line at $1.6 \mu \mathrm{m}$ (light gray line in Fig. 4), option 2 is halfway towards a $\mathrm{CO}_{2}$ line at $2 \mu \mathrm{m}$ (dark gray). The latter is roughly two times more favourable than at $1.6 \mu \mathrm{m}$ thanks to the presence of stronger lines which enable on-line positions further away in the wing of the line. Option 2 at $1645 \mathrm{~nm}$ stands out as exceptionally sensitive in the lower troposphere due to a particularly favourable wavelength separation between the two line multiplets that form the trough. Both multiplets consist of three strong methane lines each with intensities varying between about 0.5 and $1.2 \times 10^{-21} \mathrm{~cm}^{-1} /\left(\right.$ molecule $\left.\mathrm{cm}^{-2}\right)$, with pressure broadening coefficients between 0.041 and $0.057 \mathrm{~cm}^{-1} \mathrm{~atm}^{-1}$, and with pressure shift coefficients between -0.0018 and $-0.0218 \mathrm{~cm}^{-1} \mathrm{~atm}^{-1}$. Their lower energy levels and temperature dependencies of the broadening coefficients are almost identical, with $220 \mathrm{~cm}^{-1}$ and 0.85 respectively.

Table 1 lists the main characteristics and IPDA uncertainty estimates for all four trough options. We define the figure of merit of the weighting function as the ratio between the integral of the normalized weighting function in the lowest 
$\mathrm{km}$, i.e. below the dotted horizontal line in Fig. $4(z<1 \mathrm{~km}$, $p>894 \mathrm{hPa}$ for a US standard atmosphere) and the integral of a theoretical normalized uniform weighting function in the same layer. The figure of merit expresses the sensitivity of the measurement to variations of the methane mixing ratio near the surface. Indeed, for a given variation of methane in the lower troposphere, whose detection is the primary focus of the mission, a weighting function with higher sensitivity in the lower troposphere gives more impact onto the measured column $\mathrm{XCH}_{4}$. Uncertainties in the auxiliary parameters of the retrieval, i.e. atmospheric temperature and humidity profiles, and surface pressure, impinge on the $\mathrm{XCH}_{4}$ precision. They are assessed using the procedure described in the Appendix, and listed in Table 1. All uncertainties are normalised by the corresponding weighting function figure of merit in order to allow for neutral comparisons, because a weighting function with higher sensitivity in the lower troposphere gives a useful signal that is proportionally larger against a source of uncertainty on $\mathrm{XCH}_{4}$ of a given magnitude. Since they are essentially quasi-random and uncorrelated, all uncertainties can be added geometrically.

In agreement with a previous study (Ehret and Kiemle, 2005), the uncertainty due to an uncertainty in surface pressure of $1 \mathrm{hPa}$ dominates with $\sim 0.1 \%$. On global average state-of-the-art NWP surface pressure errors are smaller, $\sim 0.7 \mathrm{hPa}$ (Dee et al., 2011). They can however become considerably larger, particularly near cyclones in data-sparse regions such as oceans. Yet there, the presence of clouds anyway inhibits lidar measurements. The resulting methane uncertainty is to first order proportional to the surface pressure uncertainty that can be provided by state-of-the-art NWP models. We estimated uncertainties of the humidity and temperature profiles using globally averaged vertical error covariances calculated from ECMWF forecast difference data (Elias Holm, personal communication, 2011) as detailed in the Appendix. The variation range in Table 1 represents the uncertainty spread for different climates, also detailed in the Appendix. The total $\mathrm{XCH}_{4}$ uncertainty of $\sim 0.12 \%$ is nearly an order of magnitude lower than the uncertainty due to instrument noise, assessed in Sect. 5. The differences between the four options are subtle, but option 2 displays a particularly low sensitivity towards uncertainties in the humidity profile thanks to the possibility of a judicious choice of offline wavelength as described in the Appendix. This choice also yields the smallest spacing between on- and off-line wavelengths, thus minimising the impact of any wavelength dependence of surface reflectance and atmospheric extinction. The methane trough at $1645 \mathrm{~nm}$ is therefore selected as baseline in the following.

\section{Performance model}

The precision of space-based lidar measurements is influenced by a set of instrument, platform and geophysical (earth surface and atmosphere) parameters. We constructed a performance model that simulates the physics of the measurements with respect to the instrumental and environmental constraints. It is used to study the significance of each parameter and to quantify the expected measurement precision. Similar performance analyses investigated space-based and airborne differential absorption lidar for profiling water vapour (Ismail and Browell, 1989), and IPDA lidars for other greenhouse gases (Ehret and Kiemle, 2005; Bruneau et al., 2006). The model's core components are sketched in Fig. 5 and comprise program modules that provide the instrument, platform and geophysical input parameters on the base of technical specifications and auxiliary models. The instrument's detector needs particular attention since it is a significant source of noise, as shown in the next section. Various photodiode detectors can be modelled to study their respective performance. Besides vertical profiles of pressure and temperature from standard climates, further atmospheric components of the model, adopted from Ehret and Kiemle (2005), include a variety of aerosol and cloud backscatter and extinction coefficient profiles, as well as an assessment of the solar background radiation.

Initial parametric analyses in a standardised geophysical environment serve to test the model, to identify critical parameters, and to define a physically and technically realistic set of instrument and platform parameters. Thereafter, all parameters are varied subsequently within reasonable limits in order to study the overall systems' response onto the measurement precision. In a final phase, the performance is optimised iteratively in small steps towards a baseline parameter set, following minimum power, space and cost criteria. This baseline configuration can subsequently be exposed to different geophysical situations in order to study the variations of measurement precision over the globe. This simulation runs as follows: After initialisation with the baseline parameter set and modification of the selected instrument or platform parameter, the desired geophysical environment is constituted, the on- and off-line absorption cross sections are computed, and the IPDA lidar equation with error propagation and noise terms returns the simulated methane column precision. Other key variables such as backscatter intensity, solar background radiation, and noise equivalent power (NEP) incident on the detector are additionally available for comprehensive investigations.

Table 2 lists the main parameters of the baseline, also used for the MERLIN phase A studies. It builds on a laser concept with power budgets estimated practical for space. Both transmitter and receiver fit into a small satellite eligible for a "piggy-back" launch together with a larger payload, to limit mission costs. The average laser output power in Table 2 is the product of pulse energy and repetition frequency: 


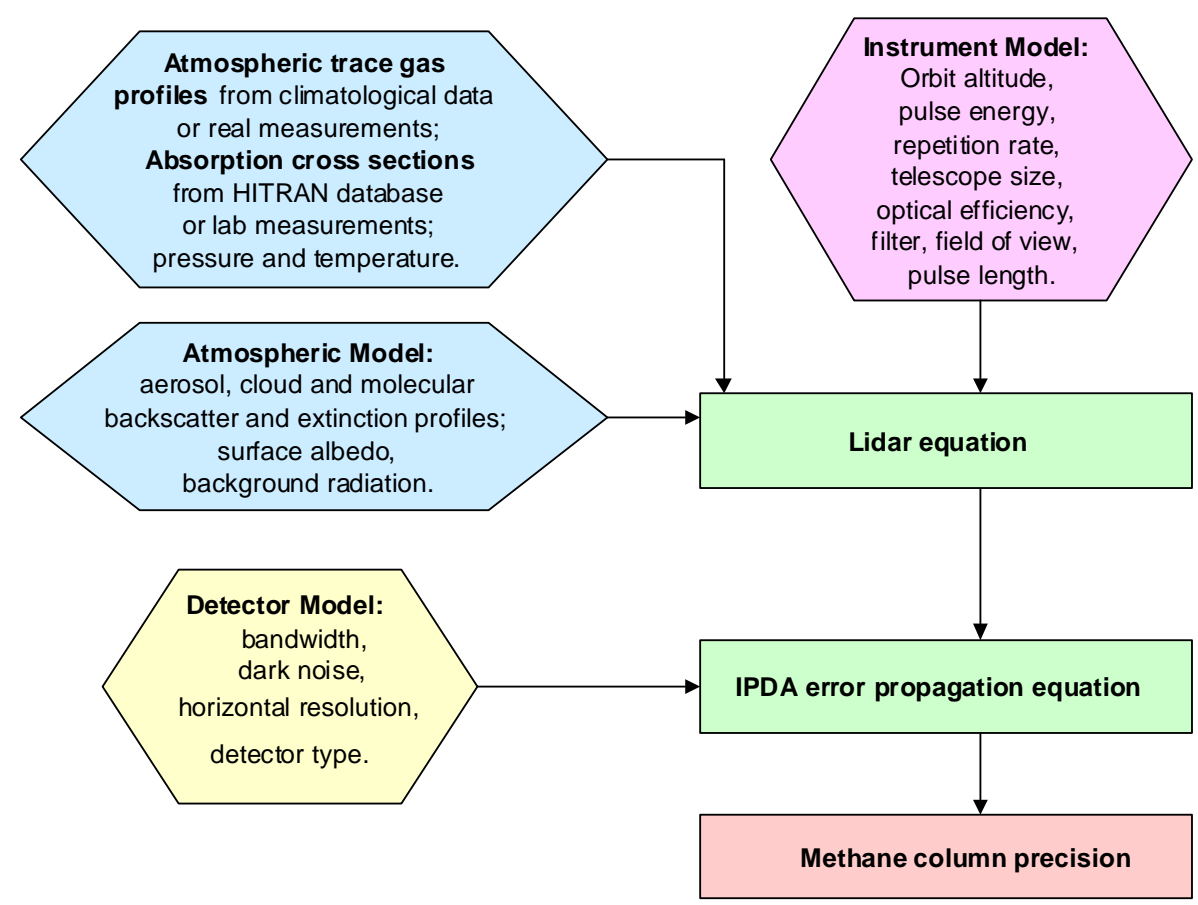

Fig. 5. Main components of the differential absorption lidar simulation model. Input of auxiliary parameters and models in hexagons, core equations and result in rectangles.

$9.0 \mathrm{~mJ} \times 50 \mathrm{~Hz}=0.45 \mathrm{~W}$. Since two pulses are needed to generate the on- and off-line wavelengths, the measurement's repetition rate is $25 \mathrm{~Hz}$, with a measurement every $280 \mathrm{~m}$, as Fig. 1 illustrates. The effective pulse length ( $\Delta t_{\text {eff }}$ in Eq. 1$)$ takes into account the stretching of the emitted laser pulse by surface undulations within the $135 \mathrm{~m}$ diameter surface spot, and by the impulse response time of the detector/amplifier system, as described in Ehret et al. (2008). The emitted pulse is assumed to last $15 \mathrm{~ns}$, which is above the Fourier limit of a Gaussian-shaped pulse of $7.4 \mathrm{~ns}$ for a sufficiently small laser spectral bandwidth of $60 \mathrm{MHz}$. Terrain undulations or sea wave amplitudes are estimated to $10 \mathrm{~m}$ which corresponds to a stretching by $67 \mathrm{~ns}$. The use of a low-pass filter of third order with $3 \mathrm{MHz}$ cut-off gives a detector impulse response time $\tau$ of $111 \mathrm{~ns}$. All three time spans are indicated at full-width half-mean (FWHM), assuming Gaussian shapes. Their convolution is consequently expressed by their rms sum which gives an effective, stretched pulse length of $\Delta t_{\text {eff }}=130 \mathrm{~ns}$. The dominant factor is the low-pass filter needed to limit high-frequency noise. Its cut-off frequency level also determines the precision in the measurement of the height of the atmospheric column. Ehret et al. (2008) assumed that a ranging precision of $2 \mathrm{~m}$ could be achieved with a detection bandwidth of $3 \mathrm{MHz}$. The resulting methane column uncertainty would then be $\sim 0.03 \%$ which is fairly negligible.

The need for both short impulse response time and high detection sensitivity leads to the selection of InGaAs avalanche photo diodes (APD) that are commercially available. Experience with our own amplifier developments for airborne lidars helped define realistic detector and amplifier parameters. The receiver's total optical efficiency of $\eta=65 \%$ is based on knowledge gained from the A-SCOPE IPDA lidar study (Ingmann et al., 2008). A sun-synchronous dawn-dusk polar orbit is favoured for uninterrupted solar power supply, giving a minimum sun zenith angle of about $75^{\circ}$. The solar nadir radiance at the telescope entrance that results from sunlight incident with this angle and scattered back to nadir direction by the earth's surface and atmosphere amounts to $5.1 \mathrm{~mW} \mathrm{~m}^{-2} \mathrm{~nm}^{-1} \mathrm{sr}^{-1}$ at $1645.6 \mathrm{~nm}$. This is low compared to the detector's dark current, as detailed below. Since most sun zenith angles on that type of orbit are larger, implying less solar radiance, this value represents a "worst case" solar background level. The earth's thermal radiation is comparably negligible. The result was obtained with the libRadtran radiative transfer program (Mayer and Kylling, 2005) using standard atmosphere and aerosol profiles, and a surface reflectance of $\rho=0.1 \mathrm{sr}^{-1}$ which represents an average for vegetation at $1.6 \mu \mathrm{m}$, as measured by Amediek et al. (2009). The along-track resolution of $50 \mathrm{~km}$ implies horizontal averaging, as sketched in Fig. 1, and represents the result of a compromise between high precision $(\sim 1 \%)$ and spatial resolution. Since individual MERLIN measurements are uncorrelated and will be available for ground processing (estimates of the required data rate fit into the available typical downlink telemetry rates which therefore imposes no 
Table 2. Baseline configuration for the main instrument, platform, and geophysical parameters of the space-based methane lidar MERLIN that provides a methane column measurement precision of $0.8 \%$.

\begin{tabular}{ll}
\hline \multicolumn{2}{c}{ Laser Transmitter } \\
\hline Pulse energy & $9.0 \mathrm{~mJ}$ \\
Average output power & $0.45 \mathrm{~W}$ \\
Pulse repetition frequency & $50 \mathrm{~Hz}$ \\
Effective pulse length & $130 \mathrm{~ns}$ FWHM \\
Laser beam divergence & $0.27 \mathrm{mrad}$ FWHM \\
Spot diameter at m.s.l. & $135 \mathrm{~m}$ \\
On-line wavelength & $1645.552 \mathrm{~nm}$ \\
Off-line wavelength & $1645.846 \mathrm{~nm}$ \\
\hline & Receiver \\
\hline Type & Cassegrain telescope \\
Primary mirror diameter & $0.55 \mathrm{~m}$ \\
Optical bandwidth & $1.0 \mathrm{~nm}$ FWHM \\
Total optical efficiency & 0.65 \\
\hline \multicolumn{1}{c}{ Detector and amplifier } \\
\hline Type & InGaAs APD \\
Part number & IAG200T6 \\
Manufacturer & Laser Components DG, Inc. \\
Internal gain $M$ & 10 \\
Quantum efficiency $\eta_{\mathrm{q}}$ & 0.6 \\
Excess noise factor $F$ & 3.2 \\
Impulse response time $\tau$ & $111 \mathrm{~ns}$ \\
Noise equivalent power & $43 \mathrm{fW} / \sqrt{ } \mathrm{Hz}$ \\
\hline
\end{tabular}

Platform and environment

\begin{tabular}{|c|c|}
\hline Orbit type & Polar, sun synchronous, dawn/dusk \\
\hline Orbit altitude & $506 \mathrm{~km}$ \\
\hline Footprint velocity & $7.0 \mathrm{~km} \mathrm{~s}^{-1}$ \\
\hline Along-track resolution & $50 \mathrm{~km}$ \\
\hline Pressure, temperature & standard atmosphere \\
\hline Aerosol & $\begin{array}{l}\text { median profile } \\
\text { (Vaughan et al., 1995) }\end{array}$ \\
\hline Methane mixing ratio & $\begin{array}{l}1.774 \text { ppmv in the troposphere } \\
\text { (Forster et al., 2007) }\end{array}$ \\
\hline Simulation top altitude & $62 \mathrm{~km}$ \\
\hline Surface reflectance & $0.1 \mathrm{sr}^{-1}$ \\
\hline Solar background radiance & $5.1 \mathrm{~mW} \mathrm{~m}^{-2} \mathrm{~nm}^{-1} \mathrm{sr}^{-1}$ \\
\hline Spectroscopic data base & $\begin{array}{l}\text { HITRAN } 2008 \\
\text { (Rothman et al., 2009) }\end{array}$ \\
\hline
\end{tabular}

on-board horizontal averaging), alternative averaging procedures adapted to the methane emission strengths or to measurements in broken clouds are possible.

For this baseline concept, speckle noise, estimated after Ehret et al. (2008), is found negligible, thanks to a relatively large field-of-view and surface spot size. The latter is the result of a compromise between speckle and on-/offline overlap uncertainties that decrease with spot size (Amediek et al., 2009), and solar background radiation that increases with the field-of-view. Setting aside the effect of uncertainties in the denominator of Eq. (3), which can safely be assumed not correlated with instrumental noise and is therefore treated separately in the Appendix and in Sect. 3, the derivation of Eq. (3) relates the relative single-measurement uncertainty on $\mathrm{XCH}_{4}$ to the relative uncertainties on the backscattered optical power and pulse energy measurements:

$$
\frac{\delta X \mathrm{CH}_{4}}{X \mathrm{CH}_{4}}=\frac{1}{2 \cdot \mathrm{DAOD}} \cdot \sqrt{\left(\frac{\delta P_{\mathrm{on}}}{P_{\mathrm{on}}}\right)^{2}+\left(\frac{\delta P_{\text {off }}}{P_{\text {off }}}\right)^{2}+\left(\frac{\delta E_{\mathrm{on}}}{E_{\mathrm{on}}}\right)^{2}+\left(\frac{\delta E_{\mathrm{off}}}{E_{\text {off }}}\right)^{2}} .
$$

In practice, the measurement of the pulse energies can be made as precise as necessary by splitting out a sufficient fraction of the emitted energy, so that the two last terms in the sum of Eq. (5) can be neglected with respect to the two first terms. After averaging $n$ uncorrelated individual measurements along the accumulation length (cf. Fig. 1), and introducing $\mathrm{SNR}_{\text {on }}=P_{\text {on }} / \delta P_{\text {on }}$ and $\mathrm{SNR}_{\text {off }}=P_{\text {off }} / \delta P_{\text {off }}$, the single-measurement signal-to-noise-ratios on $P_{\mathrm{on}}$ and $P_{\mathrm{off}}$ from Eq. (1), we obtain:

$$
\frac{\delta X \mathrm{CH}_{4}}{X \mathrm{CH}_{4}}=\frac{1}{2 \cdot \mathrm{DAOD}} \cdot \sqrt{\frac{\mathrm{SNR}_{\mathrm{on}}^{-2}+\mathrm{SNR}_{\mathrm{off}}^{-2}}{n}} .
$$

The total noise $\delta P$ mainly consists of (1) the detector's NEP, (2) the shot noise of the laser, and (3) the shot noise of the solar background photons. The shot noise $N$ of a signal $S$ is determined by Poisson statistics: $N=\sqrt{ } S$. To size the dominating noise sources it is useful to compare the number of "dark photons" $N_{\text {det }}$, i.e. photons equivalent to the dark current of the detector-amplifier system, with the number of laser and solar photons incident on the detector. Following Ismail and Browell (1989), $N_{\text {det }}$ is related to the detector-amplifier NEP via:

$N_{\mathrm{det}}=\frac{\eta_{\mathrm{q}} \tau}{2 F} \cdot\left(\frac{\lambda \cdot \mathrm{NEP}}{h c}\right)^{2}$.

Here $\eta_{\mathrm{q}}$ is the quantum efficiency of the APD, $\tau$ the abovementioned detector-amplifier impulse response time, $\lambda$ the wavelength, $h$ Planck's constant and $c$ the speed of light. The excess noise factor $F$, accounts for the statistical fluctuations of the charge multiplication in the APD. In an ideal detector with zero NEP, $N_{\text {det }}$ photons would generate the dark current electrons of the real detector. Finally, the number of solar background photons $N_{\text {back }}$ is obtained from the nadir radiance, and the laser photons $N_{\text {sig }}$ hitting the sensitive detector area are determined by the lidar equation (Eq. 1). Since the laser, solar and detector noise contributions are uncorrelated, they can be added, and the total number of noise photoelectrons generated in the detector is expressed in the denominator of Eq. (8), using Poisson statistics and following Ismail and Browell (1989). With the APD gain M the signal photoelectrons are given by $\eta_{\mathrm{q}} \cdot M \cdot N_{\text {sig }}$, and the SNR of Eq. (6) finally adopts the form: 
Table 3. Number of photons per range gate $(\tau c / 2=16.7 \mathrm{~m})$ reaching the detector for three different regimes of noise representing the global spread in surface reflectance (after Amediek et al., 2009), valid for the MERLIN baseline configuration of Table 2.

\begin{tabular}{lcccccl}
\hline $\begin{array}{l}\text { surface } \\
\text { type }\end{array}$ & $\begin{array}{c}1.65 \mu \mathrm{m} \text { surface } \\
\text { reflectance } \\
\rho\end{array}$ & $\begin{array}{c}\text { online } \\
\text { signal } \\
N_{\text {sig }}\end{array}$ & $\begin{array}{c}\text { Solar } \\
\text { background } \\
N_{\text {back }}\end{array}$ & $\begin{array}{c}\text { dark } \\
\text { photons } \\
N_{\text {det }}\end{array}$ & $\begin{array}{c}\text { online } \\
\text { SNR }\end{array}$ & $\begin{array}{l}\text { noise } \\
\text { regime }\end{array}$ \\
\hline water & $0.02 \mathrm{sr}^{-1}$ & 163 & 18 & 1300 & 1.8 & high-noise \\
vegetation & $0.10 \mathrm{sr}^{-1}$ & 1022 & 113 & 1300 & 9.0 & baseline \\
desert & $0.30 \mathrm{sr}^{-1}$ & 3092 & 341 & 1300 & 20 & low-noise \\
\hline
\end{tabular}

$$
\begin{aligned}
\mathrm{SNR} & =\frac{\eta_{\mathrm{q}} M N_{\text {sig }}}{M \sqrt{\eta_{\mathrm{q}} F\left(N_{\text {sig }}+N_{\text {back }}+N_{\text {det }}\right)}} \\
& =\sqrt{\frac{\eta_{q}}{F}} \cdot \frac{N_{\text {sig }}}{\sqrt{N_{\text {sig }}+N_{\text {back }}+N_{\text {det }}}} .
\end{aligned}
$$

\section{Results}

When running the performance model with the baseline configuration of Table 2 and using Eq. (8), the SNR turns out to be roughly proportional to the surface reflectance $\rho$, as expected and shown in Table 3. Low reflectance, e.g. over water, gives low return signals, and consequently low SNR. Here, the lowest value obtained from airborne measurements by Amediek et al. (2009) over sea is used as a worst case. On the other hand, high reflectance gives strong signals but, unfortunately, most regions with high reflectance are arid and consequently of little interest. Overall, the offline SNR (not shown here) is roughly a factor of two to three larger than the online SNR. Hence the measurement precision following Eq. (6) is to good approximation in inverse relationship with the online SNR and the surface reflectance, which is illustrated in the right panel of Fig. 6. Since most of the solar background radiation is due to scattering from the surface, and only a small fraction due to atmospheric scattering, there is a nearly linear relationship between $N_{\text {back }}$ and $\rho$. On the whole the solar background is relatively small, even over highly reflecting surfaces. Finally, Table 3 shows that the detector noise, expressed by the number of dark photons, dominates in both the high-noise and baseline regimes. For these calculations, the case of an off-the-shelf component was selected as a worst-case scenario. The use of a detector with better performance would significantly improve the SNR.

Figure 6 shows estimates of the measurement precision (Eq. 6) of the MERLIN baseline for a 50-km averaged methane column $\left(\mathrm{XCH}_{4}\right)$. For scattering surfaces within altitudes between 0 and $2 \mathrm{~km}$ the precision is $\sim 0.8 \%$. Since we find a minimum measurement uncertainty at $\sim 1 \mathrm{~km}$ a.s.1., the DAOD of 0.53 (Table 1) is nearly optimal. A higher DAOD would lead to a stronger curvature and to consequently higher
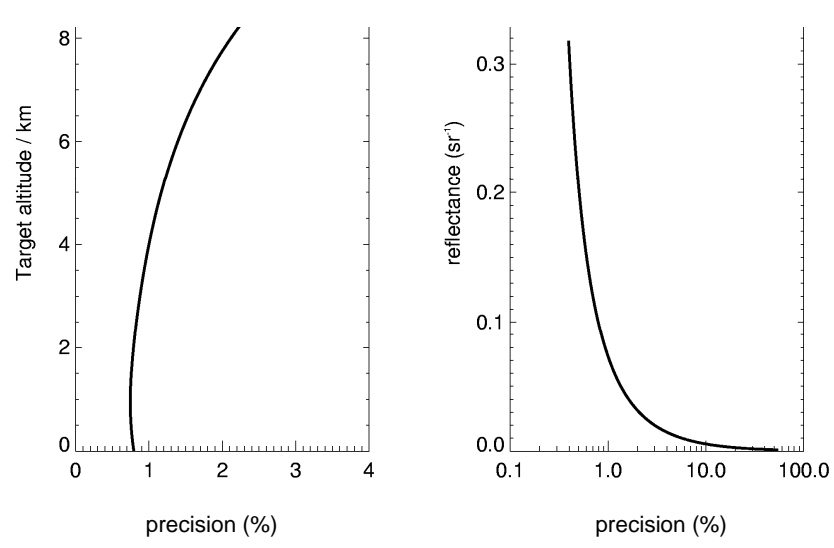

Fig. 6. Methane column measurement precision $\delta X \mathrm{CH}_{4} / X \mathrm{CH}_{4}$ for the MERLIN baseline of Table 2 as function of the scattering surface altitude (a.s.l.) (left panel), and as function of the surface reflectance of a target at sea level (right panel).

uncertainty at sea level, due to the stronger on-line signal attenuation. An atmosphere with stronger aerosol optical depth generates a similar negative effect on the measurement uncertainty, as documented in Fig. 5b of Ehret et al. (2008). On the other hand, a smaller DAOD (weaker absorption) would give a more linear relationship between precision and altitude at the cost of higher uncertainty at all levels. Here, the precision slightly degrades with altitude to $2.1 \%$ at $8 \mathrm{~km}$, due to decreasing DAOD, as expressed in Eq. (6). This is not critical since the frequency of occurrence of elevated targets such as high plains and mountains strongly decreases with altitude. Opaque clouds with high optical depth could be useful targets if their tops were sufficiently flat and distinct.

The performance model allows detailed assessments of parameters that have an impact on the measurement precision. Here, we summarise the most relevant results concerning MERLIN's four key parameters, grouped in the IPDA lidar equation (Eq. 1): average laser power $P$, telescope area $A$, orbit height $r$, and surface reflectance. While the first three are adjustable by instrument and platform design, the latter is given by the surface properties. Figures 7 to 9 show the impact of variations of these four key parameters on the methane column measurement precision. For a broad 


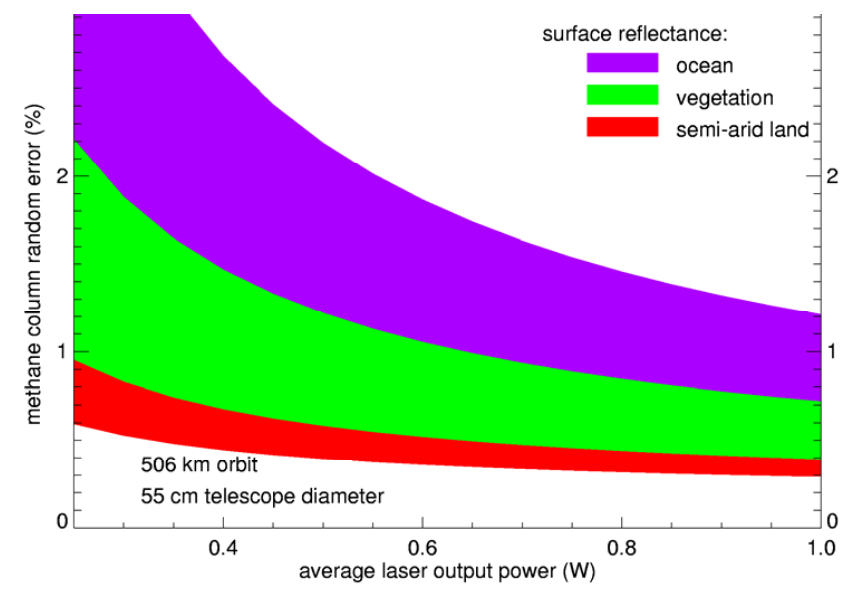

Fig. 7. Methane measurement precision $\delta X \mathrm{CH}_{4} / \mathrm{XCH}_{4}$ as function of laser power and surface reflectance, assumed to range between $0.02-0.05 \mathrm{sr}^{-1}$ for water (ocean), between $0.05-0.14 \mathrm{sr}^{-1}$ for vegetation, and $0.14-0.30 \mathrm{sr}^{-1}$ for semi-arid land and desert. The MERLIN baseline of Table 2 with $0.45 \mathrm{~W}$ and $0.1 \mathrm{sr}^{-1}$ yields a precision of $0.8 \%$.

range of variation of these parameters, here a factor of four in laser power, a factor of two in telescope diameter and orbit height, and a factor of 15 in surface reflectance, the resulting $\mathrm{XCH}_{4}$ precisions vary between 0.3 and several percent. The plots give an overview of the general instrument behaviour in various noise conditions. They exhibit an obvious transition between two different, opposite noise regimes at the left and the right side. Varying the key parameters by small amounts around the baseline in the three different noise and surface reflectance regimes of Table 3 gives the following power-law relationships for the methane measurement precision:

High noise : $\delta X \mathrm{CH}_{4} / X \mathrm{CH}_{4} \sim\left(r^{2} / P A\right)^{0.9} \cdot \mathrm{NEP}^{0.8}$.

Baseline : $\delta X \mathrm{CH}_{4} / X \mathrm{CH}_{4} \sim\left(r^{2} / P A\right)^{0.7} \cdot \mathrm{NEP}^{0.3}$.

Low noise : $\delta \mathrm{XCH}_{4} / \mathrm{XCH}_{4} \sim\left(r^{2} / P A\right)^{0.5} \cdot \mathrm{NEP}^{0.1}$.

These relationships describe proportionalities between the varied parameter and the resulting precision valid for the MERLIN baseline. A positive power-law exponent signifies strong uncertainty increase when the parameter, e.g. the orbit height $r$, increases. A negative exponent represents an inverse relationship, and an exponent close to zero means weak dependency. While the NEP is nearly insignificant in low-noise conditions, it becomes a determining parameter in high-noise, low-reflectance environments. In agreement with the lidar equation (Eq. 1), the term $r^{2} / P A$ expresses a noiseinvariant relationship between the three key instrument and platform parameters. With only square root dependency (exponent 0.5 ) at low noise, its impact is nearly linear (exponent 0.9) at high noise. All other parameters listed in Table 2

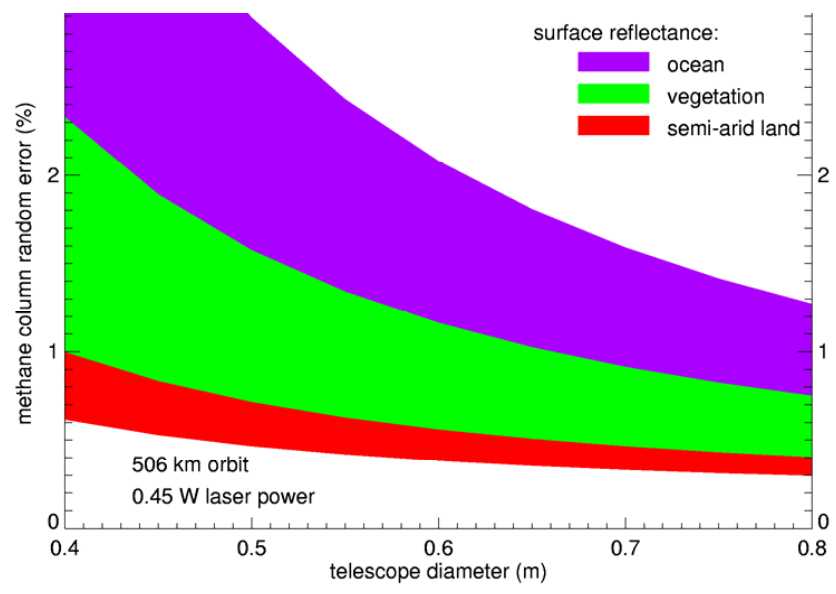

Fig. 8. Measurement precision as function of telescope diameter and surface reflectance (similar to Fig. 7). The MERLIN baseline with $0.55 \mathrm{~m}$ and $0.1 \mathrm{sr}^{-1}$ yields a precision of $0.8 \%$.

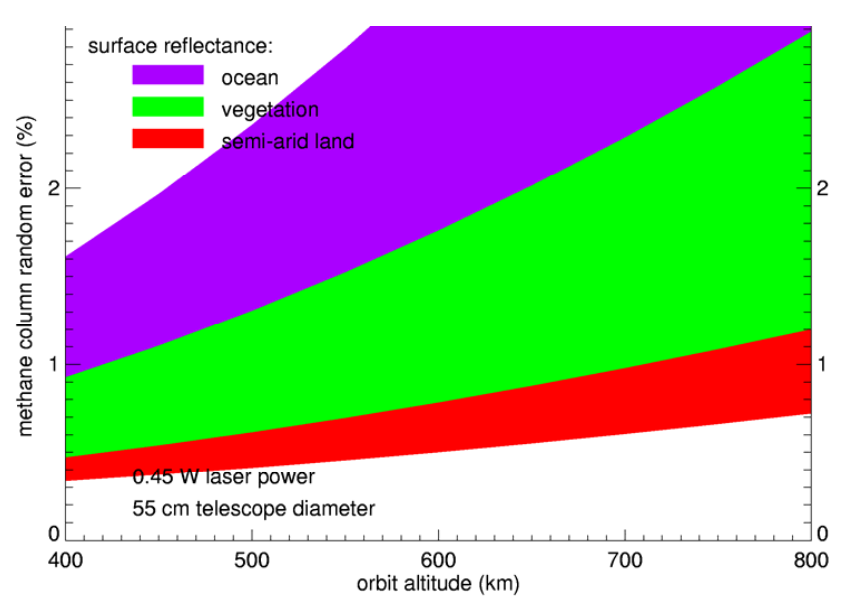

Fig. 9. Measurement precision as function of orbit height and surface reflectance (as Fig. 7). The MERLIN baseline of Table 2 with $506 \mathrm{~km}$ and $0.1 \mathrm{sr}^{-1}$ yields a precision of $0.8 \%$.

are found to be comparatively insensitive, with absolute values of power-law exponents much smaller than 0.1 . One exception is the pulse energy $E$ in high-noise conditions, scaling with $\delta X \mathrm{CH}_{4} / \mathrm{XCH}_{4} \sim E^{-0.4}$ if the average laser power $P$ is kept constant, i.e. if the PRF (pulse repetition frequency) is adjusted such that it fulfils the condition $P=E$. PRF. In other words: for low surface reflectances, higher pulse energies at lower PRF are more favourable. The baseline lies in a transition region between the two opposite noise extremes. Figures 7 to 9 and the relationships Eq. (9) to Eq. (11) allow easy assessments for instrument modifications and parameter trade-offs. For example, a system with a larger telescope $(69 \mathrm{~cm}$ in diameter; improvement) in a higher orbit $(630 \mathrm{~km}$; penalty) is expected to provide a performance that is nearly identical to the baseline system of Table 2 . 
Table 4. Influence of beam attenuation by aerosol on methane column precision. In an atmosphere with less (more) aerosol load than the median, the performance is improved (degraded) by the indicated factor. The indicated equivalent resolution would be needed to re-establish a measurement precision of $0.8 \%$, valid for the median aerosol baseline.

\begin{tabular}{lccr}
\hline $\begin{array}{l}\text { Aerosol } \\
\text { profile }\end{array}$ & $\begin{array}{c}\text { aerosol } \\
\text { optical } \\
\text { depth }\end{array}$ & $\begin{array}{c}\text { precision } \\
\text { gain/loss } \\
\text { factor }\end{array}$ & $\begin{array}{r}\text { baseline } \\
\text { equivalent } \\
\text { resolution }\end{array}$ \\
\hline lower decile & 0.01 & $0.88 \pm 0.01$ & $39 \mathrm{~km}$ \\
lower quartile & 0.03 & $0.89 \pm 0.01$ & $40 \mathrm{~km}$ \\
median & 0.11 & 1.0 & $50 \mathrm{~km}$ \\
higher quartile & 0.44 & $1.63 \pm 0.04$ & $133 \mathrm{~km}$ \\
higher decile & 1.42 & $9.58 \pm 0.58$ & - \\
\hline
\end{tabular}

Atmospheric aerosols can increase the measurement uncertainty due to scattering and absorption, as already shown by Ehret et al. (2008). To quantify this effect the performance model was run with various representative aerosol backscatter profiles based on comprehensive lidar measurements over the Atlantic Ocean at a wavelength of $10.6 \mu \mathrm{m}$ by Vaughan et al. (1995). The data were roughly scaled to $1.65 \mu \mathrm{m}$ using an altitude-dependent Angstrom exponent of 1.0 at sea level and 1.8 at $5 \mathrm{~km}$ a.s.l. to represent typical tropospheric aerosols. The aerosol profiles are grouped after their probability of occurrence using percentiles. The resulting backscatter coefficient in the baseline median aerosol profile is $2 \times 10^{-6} \mathrm{~m}^{-1} \mathrm{sr}^{-1}$ at sea level and $2 \times 10^{-9} \mathrm{~m}^{-1} \mathrm{sr}^{-1}$ at $5 \mathrm{~km}$ a.s.l. The corresponding extinction coefficients are $10^{-4} \mathrm{~m}^{-1}$ at sea level and $10^{-7} \mathrm{~m}^{-1}$ at $5 \mathrm{~km}$ a.s. 1 . Since these data are not necessarily representative for the whole globe, and since a constant Angstrom exponent between 10.6 and $1.65 \mu \mathrm{m}$ is unlikely, we cross-checked the median aerosol profile with additional lidar measurements performed over the Pacific Ocean (Menzies et al., 2002). We find good agreement between our median aerosol backscatter coefficient profile that serves as baseline in our study, and their average profile of the aerosol background load, i.e. in the absence of Asian dust and pollution layers. This supports our approach of using the Atlantic median profile as a baseline.

The results in Table 4 give an overview of the simulated precision improvement (for a cleaner than median atmosphere) or loss, relative to the median aerosol profile used as baseline. Adapting the horizontal averaging length using the square root relationship expressed in Eq. (6) would ensure constant measurement precision. The indicated factors are principally only valid for the baseline configuration of Table 2. To test this restraint, the telescope diameter was varied between $0.55 \mathrm{~m}$ and $0.69 \mathrm{~m}$. The resulting precision factor variation is indicated by the uncertainty ranges. We find that such instrument parameter modifications have low influence on the factors which consequently provide robust prognoses of the instrument's performance in the presence of aerosols.
Table 5. Impact of beam attenuation by a thin cirrus cloud layer in $9 \mathrm{~km}$ altitude on methane column precision. The indicated equivalent resolution would be needed to re-establish a measurement precision of $0.8 \%$, valid for the cloud-free baseline.

\begin{tabular}{ccr}
\hline $\begin{array}{c}\text { cirrus } \\
\text { optical } \\
\text { depth }\end{array}$ & $\begin{array}{c}\text { precision } \\
\text { loss } \\
\text { factor }\end{array}$ & $\begin{array}{r}\text { baseline } \\
\text { equivalent } \\
\text { resolution }\end{array}$ \\
\hline 0.1 & $1.15 \pm 0.01$ & $66 \mathrm{~km}$ \\
0.3 & $1.55 \pm 0.04$ & $120 \mathrm{~km}$ \\
0.5 & $2.15 \pm 0.07$ & $231 \mathrm{~km}$ \\
0.7 & $3.02 \pm 0.13$ & $456 \mathrm{~km}$ \\
\hline
\end{tabular}

Finally, ice clouds (cirrus), present over large portions of the globe, attenuate the lidar signals mainly by scattering. The clouds' optical thickness determines the $\mathrm{XCH}_{4}$ precision degradation. Table 5 displays the impact of thin cirrus with optical depths between 0.1 and 0.7 relative to the cloudfree reference atmosphere with the median aerosol profile. As for the aerosol variations, adapting the horizontal measurement resolution by averaging more under cloudy conditions could restore constant precision. For moderate cirrus with optical depths around 0.7 however, roughly a tenfold averaging length would be needed. Still, our results show that precise methane measurements beneath thin cirrus, polar stratospheric clouds, or aerosol layers are principally possible without loss of accuracy. This represents a major advance of active over passive remote sensing.

\section{Conclusions}

A major handicap to quantify the methane emissions at the Earth's surface is the lack of accurate global observations of atmospheric methane. In the frame of a German-French climate monitoring initiative, a "Methane Remote Lidar Mission" (MERLIN) onboard a small satellite in low polar orbit was proposed by DLR and its French counterpart CNES. This mission will use the differential absorption lidar technique, allowing to measure methane at night, polar winter, through broken clouds, and at low sun angles. Ideally its operation will overlap with GOSAT or an equivalent successor to exploit synergies from joint measurements with different principles and complementary viewing conditions: While the lidar can provide information on clouds and aerosol layers to improve the performance of the passive sensor, the latter will supply valuable cross-track observations to improve the representativeness of the lidar's methane measurements. Using a baseline set of lidar instrument $(0.45 \mathrm{~W}$ average laser power at $1.65 \mu \mathrm{m} ; 0.55 \mathrm{~m}$ telescope diameter), platform (506 km orbit height) and geophysical environment parameters, a parametric performance analysis was undertaken to simulate the effect of each parameter on the 
expected measurement precision. With relatively modest size this instrument could provide $50-\mathrm{km}$ averaged methane column measurement along the sub-satellite track with a precision (noise uncertainty) of about $1 \%(1 \sigma)$ over vegetation (surface reflectance $0.1 \mathrm{sr}^{-1}$ ). Key performance parameters are laser power, telescope size, orbit altitude, surface reflectance, and detector NEP, assumed $43 \mathrm{fW} \mathrm{Hz}^{-0.5}$ for an InGaAs APD. The detector noise dominates, as an off-the-shelf component was selected as a worst-case scenario. The use of a detector with better performance would significantly improve the precision. The online wavelength position within a methane absorption trough improves the near-surface measurement sensitivity, while considerably relaxing the laser's frequency stability requirement. Consequently, instrument cost, size and risk are considerably reduced. The next simulations will use high-resolution satellite observations of the global distribution and variability of clouds and surface reflectances to obtain a more precise image of MERLIN's performance in the real world.

\section{Appendix A}

Retrieval of column-weighted average dry-air mixing ratio of methane from differential atmospheric optical depth: principle and impact of uncertainties in atmospheric parameters

In this Appendix we first detail the IPDA lidar equations that govern the retrieval of $\mathrm{XCH}_{4}$, and then use them to assess the impact of uncertainties in the atmospheric parameters required for the retrieval. In particular, building on the work by Caron and Durand (2009), an improved method for the quantitative assessment of the impact of uncertainties in the water vapour profiles, and for a subsequent choice of an optimal off-line wavelength, is presented here. As mentioned in Sect. 2, the basic physical quantity measured by an IPDA lidar is the differential atmospheric optical depth, i.e. the difference in total optical depth from instrument to target between the on-line and the off-line wavelengths. According to the Beer-Lambert law, the contribution of methane to the differential atmospheric optical depth is given by:

$\mathrm{DAOD}_{\mathrm{CH}_{4}}=\int_{z=z_{\mathrm{SFC}}}^{z \mathrm{TOA}} n_{\mathrm{CH}_{4}}(z) \cdot \Delta \sigma_{\mathrm{CH}_{4}}(p(z), T(z)) \cdot \mathrm{d} z .(\mathrm{A}$

Equation (A1) is valid for a nadir-viewing IPDA lidar, with $z_{\mathrm{SFC}}$ and $z_{\mathrm{TOA}}$ as the altitudes of the scattering surface and of the top of the atmosphere, respectively, $\Delta \sigma_{\mathrm{CH}_{4}}(p, T)=\sigma_{\mathrm{CH}_{4}}\left(\lambda_{\text {on }}, p, T\right)-\sigma_{\mathrm{CH}_{4}}\left(\lambda_{\text {off }}, p, T\right)$ as the pressure and temperature dependent differential absorption cross section of methane for the considered on-/off-line wavelength pair, and $n_{\mathrm{CH}_{4}}(z)$ as the methane molecule number density. For common use the dry-air volume mixing ratio
$\mathrm{vmr}_{\mathrm{CH}_{4}}$ is required, and with $n_{\mathrm{dry} \text {-air }}$ as the dry-air molecule number density, the methane DAOD becomes:

$\mathrm{DAO}_{\mathrm{CH}_{4}}=\int_{z=z \mathrm{sFC}}^{z \mathrm{TOA}} \operatorname{vmr}_{\mathrm{CH}_{4}}(z) \cdot n_{\mathrm{dry}-\mathrm{air}}(z) \cdot \Delta \sigma_{\mathrm{CH}_{4}}(p(z), T(z)) \cdot \mathrm{d} z$.

In the following it is more convenient to substitute altitude $z$ by pressure $p$. Assuming hydrostatic equilibrium and ideal gases, this can be expressed by:

$\mathrm{d} p=-\left(m_{\text {dry-air }}+m_{\mathrm{H}_{2} \mathrm{O}} \cdot \operatorname{vmr}_{\mathrm{H}_{2} \mathrm{O}}\right) \cdot n_{\text {dry-air }} \cdot g \cdot \mathrm{d} z,(\mathrm{~A} 3)$

where $m_{\mathrm{dry} \text {-air }}$ and $m_{\mathrm{H}_{2} \mathrm{O}}$ are the molecular weights of dry air and water vapour respectively, $\mathrm{vmr}_{\mathrm{H}_{2} \mathrm{O}}$ is the dry-air volume mixing ratio of water vapour, proportional to the ratio of the densities of water vapour and dry air, and $g$ is the Earth's gravitational acceleration. Then, Eq. (A2) becomes:

$\mathrm{DAOD}_{\mathrm{CH}_{4}}=\int_{p=0}^{p_{\mathrm{SFC}}} \operatorname{vmr}_{\mathrm{CH}_{4}}(p)$

$$
\cdot \frac{\Delta \sigma_{\mathrm{CH}_{4}}(p, T(p))}{g \cdot\left(m_{\text {dry-air }}+m_{\mathrm{H}_{2} \mathrm{O}} \cdot \operatorname{vmr}_{\mathrm{H}_{2} \mathrm{O}}(p)\right)} \cdot \mathrm{d} p,
$$

where $p_{\mathrm{SFC}}$ is the atmospheric pressure at the scattering surface. Introducing:

$\mathrm{WF}_{\mathrm{CH}_{4}}(p)=\frac{\Delta \sigma_{\mathrm{CH}_{4}}(p, T(p))}{g \cdot\left(m_{\text {dry-air }}+m_{\mathrm{H}_{2} \mathrm{O}} \cdot \operatorname{vmr}_{\mathrm{H}_{2} \mathrm{O}}(p)\right)}$,

DAOD $\mathrm{CH}_{4}$ appears proportional to $\mathrm{XCH}_{4}$, a weighted average of the methane dry-air volume mixing ratio over the whole column:

$$
\begin{aligned}
\operatorname{DAOD}_{\mathrm{CH}_{4}} & =\left(\int_{p=0}^{p}{ }_{\mathrm{SFC}} \mathrm{WF}_{\mathrm{CH}_{4}}(p) \cdot \mathrm{d} p\right) \\
& \cdot \frac{\int_{p=0}^{p=0} \operatorname{vmr}_{\mathrm{CH}_{4}}(p) \cdot \mathrm{WF}_{\mathrm{CH}_{4}}(p) \cdot \mathrm{d} p}{\left(\int_{p=0}^{p_{\mathrm{SFC}}} \mathrm{WF}_{\mathrm{CH}_{4}}(p) \cdot \mathrm{d} p\right)} \\
= & \left(\int_{p=0}^{p_{\mathrm{SFC}}} \mathrm{WF}_{\mathrm{CH}_{4}}(p) \cdot \mathrm{d} p\right) \cdot X \mathrm{CH}_{4} .
\end{aligned}
$$

$\mathrm{WF}_{\mathrm{CH}_{4}}(p)$ is commonly referred to as the "pressure weighting function" or simply the "weighting function", even though the true weighting function, in mathematical terms, is $\mathrm{WF}_{\mathrm{CH}_{4}}(p)$ normalized by its integral. It is worth noting that column-weighted averages of other similar quantities, such as the humid-air mixing ratio of methane, can be defined and derived by rearranging the terms in Eqs. (A2) or (A4). These quantities are however not proportional to each other 
in the general case, because the resulting weighting functions are different. The retrieval of $\mathrm{XCH}_{4}$ is basically a matter of determining the scaling factor in Eq. (A6) and subsequently converting the measured $\mathrm{DAOD}_{\mathrm{CH}_{4}}$ via the simple retrieval equation:

$$
X \mathrm{CH}_{4}=\frac{\mathrm{DAOD}_{\mathrm{CH}_{4}}}{\left(\int_{p=0}^{p \mathrm{SFC}} \mathrm{WF}_{\mathrm{CH}_{4}}(p) \cdot \mathrm{d} p\right)} .
$$

Equations (A5) and (A7) show that the determination of the scaling factor requires the knowledge of $\Delta \sigma_{\mathrm{CH}_{4}}\left(\lambda_{\text {on }}, \lambda_{\text {off }}, p, T\right), T(p), \operatorname{vmr}_{\mathrm{H}_{2} \mathrm{O}}(p)$ and $p_{\mathrm{SFC}}$. The differential absorption cross-section for the selected wavelength pair will be determined from dedicated spectroscopic studies. $p_{\mathrm{SFC}}, T(p)$ and $\mathrm{vmr}_{\mathrm{H}_{2} \mathrm{O}}(p)$, on the other hand, will be extracted from analysis fields of numerical weather prediction (NWP) models. The pressure at the target, $p_{\mathrm{SFC}}$ can be determined by linking the known platform altitude and the measured lidar range, readily accessible from the measurement itself in the case of a pulsed lidar, with the pressure levels of the NWP model using a common reference geoid. The relative sensitivity of $\mathrm{XCH}_{4}$ to $p_{\mathrm{SFC}}$ is obtained by partial differentiation of Eq. (A7):

$$
\begin{gathered}
\frac{1}{X \mathrm{CH}_{4}} \cdot \frac{\partial X \mathrm{CH}_{4}}{\partial p_{\mathrm{SFC}}}=\frac{-\frac{\partial}{\partial p_{\mathrm{SFC}}}\left(\int_{p=0}^{p_{\mathrm{SFC}}} \mathrm{WF}_{\mathrm{CH}_{4}}(p) \cdot \mathrm{d} p\right)}{\left(\int_{p=0}^{p \mathrm{SFC}} \mathrm{WF}_{\mathrm{CH}_{4}}(p) \cdot \mathrm{d} p\right)} \\
=\frac{-\mathrm{WF}_{\mathrm{CH}_{4}}\left(p_{\mathrm{SFC}}\right)}{\left(\int_{p=0}^{p_{\mathrm{SFC}}} \mathrm{WF}_{\mathrm{CH}_{4}}(p) \cdot \mathrm{d} p\right)}
\end{gathered}
$$

which shows that its absolute value is equal to the value of the integral-normalized weighting function at the scattering surface. Equation (A8) is used to compute the uncertainty on $\mathrm{XCH}_{4}$ associated with a $1 \mathrm{hPa}$ uncertainty on $p_{\mathrm{SFC}}$ for each candidate on-/off-line wavelength pair in Table 1.

As stated in Sect. 2, the total DAOD measured by the instrument is identical to $\mathrm{DAOD}_{\mathrm{CH}_{4}}$ only if the differential contribution of all trace gases other than methane is negligible for the selected wavelength pair. The high natural variability of water vapour means it generally produces a more critical interference than the other, well-mixed trace gases such as $\mathrm{CO}_{2}$ which, to first order, only give rise to a constant offset on DAOD that can be easily taken into account. In previous approaches, the impact of water vapour on the measurement uncertainty was minimized by selecting an off-line wavelength for which the water vapour optical depth is equal to the water vapour on-line optical depth. Here, instead, we follow the approach of Caron and Durand (2009), i.e. we assume a priori that the contribution of water vapour, $\mathrm{DAOD}_{\mathrm{H}_{2} \mathrm{O}}$, first needs to be accounted for. In comparison to Eq. (A7) this leads to a slightly more complex retrieval equation:

$$
X \mathrm{CH}_{4}=\frac{\text { DAOD }- \text { DAOD }_{\mathrm{H}_{2} \mathrm{O}}}{\int_{p=0}^{p \mathrm{SFC}} \mathrm{WF}_{\mathrm{CH}_{4}}(p) \cdot \mathrm{d} p}
$$

where a set of equations identical to Eqs. (A1)-(A4) but applied to water vapour would show that:

$$
\begin{aligned}
\operatorname{DAOD}_{\mathrm{H}_{2} \mathrm{O}} & =\int_{p=0}^{p_{\mathrm{SFC}}} \operatorname{vmr}_{\mathrm{H}_{2} \mathrm{O}}(p) \\
& \cdot \frac{\Delta \sigma_{\mathrm{H}_{2} \mathrm{O}}(p, T(p))}{g \cdot\left(m_{\text {dry-air }}+m_{\mathrm{H}_{2} \mathrm{O}} \cdot \operatorname{vmr}_{\mathrm{H}_{2} \mathrm{O}}(p)\right)} \cdot \mathrm{d} p .
\end{aligned}
$$

Assuming in the following that $p_{\mathrm{SFC}}$ corresponds to the highest pressure level $n$ of the NWP model, the discrete equivalent of Eq. (A9) can be written:

$$
X \mathrm{CH}_{4}=\frac{\mathrm{DAOD}-\mathrm{DAOD}_{\mathrm{H}_{2} \mathrm{O}}}{\sum_{i=1}^{n} \mathrm{WF}_{\mathrm{CH}_{4}}^{i} \cdot \mathrm{d} p_{i}}
$$

where $\mathrm{d} p_{i}$ are the thicknesses of the $n$ pressure levels of the NWP model, and $\mathrm{WF}_{\mathrm{CH}_{4}}^{i}$ is the value of the weighting function at the $i$-th pressure level. Discrete equivalents of Eqs. (A5) and (A10) can be similarly derived. Equation (A11) shows that, for a given DAOD, $\mathrm{XCH}_{4}$ can essentially be seen as a function of $n$ auxiliary variables describing the temperature profile and $n$ auxiliary variables describing the water vapour profile.

The following treats the uncertainties on $\mathrm{XCH}_{4}$ induced by uncertainties in these temperature and water vapour profiles. For an erroneous water vapour mixing ratio profile $v r_{\mathrm{H}_{2} \mathrm{O}_{i}}+$ dvmr $_{\mathrm{H}_{2} \mathrm{O}_{i}}$ with sufficiently small errors dvmr $\mathrm{H}_{2} \mathrm{O}_{i}$, the subsequent $\mathrm{XCH}_{4}$ uncertainty $\mathrm{d} X \mathrm{CH}_{4_{\mathrm{vmr}_{\mathrm{H}} \mathrm{O}}}$ can be approximated using a first-order Taylor development of $\mathrm{XCH}_{4}$ :

$$
\mathrm{d} X \mathrm{CH}_{\mathrm{vmmr}_{\mathrm{H}_{2} \mathrm{O}}}=\sum_{i} \frac{\partial X \mathrm{CH}_{4}}{\partial \mathrm{vmr}_{\mathrm{H}_{2} \mathrm{O}_{i}}}\left(T_{i}, \mathrm{vmr}_{\mathrm{H}_{2} \mathrm{O}_{i}}\right) \cdot \mathrm{dvmr}_{\mathrm{H}_{2} \mathrm{O}_{i}} .
$$

Introducing the corresponding random variables $\delta \mathrm{vmr}_{\mathrm{H}_{2} \mathrm{O}_{i}}$ and $\delta X \mathrm{CH}_{4_{\mathrm{vmr}_{\mathrm{H}} \mathrm{O}} \mathrm{O}}$, random uncertainties on $\mathrm{vmr}_{\mathrm{H}_{2} \mathrm{O}_{i}}$ at each pressure level $i$ and resulting random uncertainty on $\mathrm{XCH}_{4}$, respectively, and by definition of the variance:

$$
\begin{aligned}
\left\langle\delta X \mathrm{CH}_{4_{\mathrm{vmr}} \mathrm{O}}^{2}\right\rangle & =\left\langle\left(\sum_{i} \frac{\partial X \mathrm{CH}_{4}}{\partial \mathrm{vmr}_{\mathrm{H}_{2} \mathrm{O}_{i}}}\left(T_{i}, \mathrm{vmr}_{\mathrm{H}_{2} \mathrm{O}_{i}}\right) \cdot \delta \mathrm{vmr}_{\mathrm{H}_{2} \mathrm{O}_{i}}\right)\right. \\
& \left.\cdot\left(\sum_{j} \frac{\partial X \mathrm{CH}_{4}}{\partial \mathrm{vmr}_{\mathrm{H}_{2} \mathrm{O}_{j}}}\left(T_{j}, \mathrm{vmr}_{\mathrm{H}_{2} \mathrm{O}_{j}}\right) \cdot \delta \mathrm{vmr}_{\mathrm{H}_{2} \mathrm{O}_{j}}\right)\right\rangle,
\end{aligned}
$$

we obtain the following expression for the standard deviation of $\mathrm{XCH}_{4}$ related to water vapour uncertainties: 


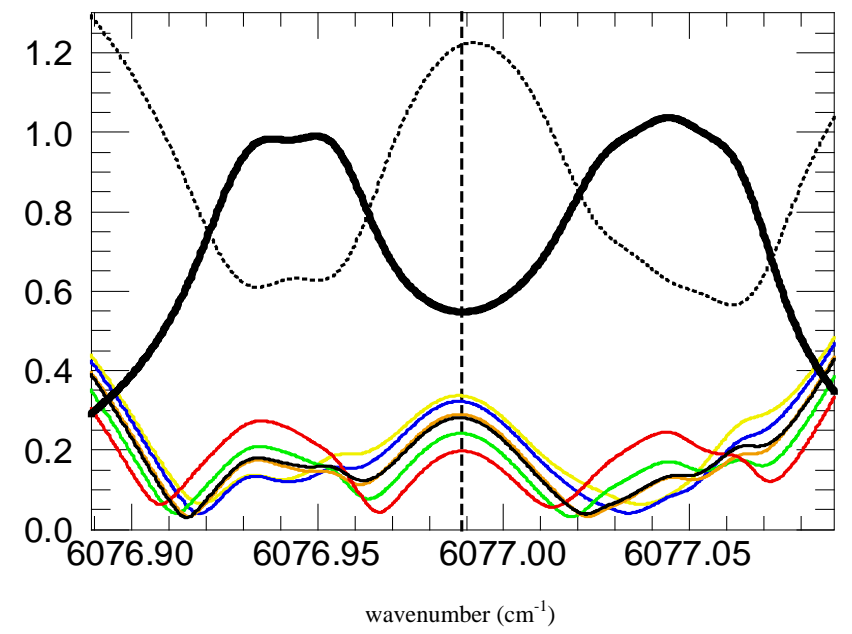

Fig. A1. Optical depth of methane around the most favorable methane line multiplet at $1645.6 \mathrm{~nm}$ (thick solid; zoom of Fig. 3) and weighting function figure of merit (dotted). Colored: Relative $\mathrm{XCH}_{4}$ uncertainty in \%o due to temperature profile uncertainties as function of on-line wavenumber for six representative climates (black: US standard, red: tropical, orange: mid-latitude summer, green: mid-latitude winter, blue: sub-arctic summer, yellow: subarctic winter), normalized by the weighting function figure of merit. Vertical dashed line: position of nominal on-line wavelength according to Table 1.

$\operatorname{std}\left(\delta X \mathrm{CH}_{4 \mathrm{vmr}_{\mathrm{H}_{2} \mathrm{O}}}\right)$

$=\sqrt{\sum_{i, j} \frac{\partial X \mathrm{CH}_{4}}{\partial \mathrm{vmr}_{\mathrm{H}_{2} \mathrm{O}_{i}}}\left(T_{i}, \mathrm{vmr}_{\mathrm{H}_{2} \mathrm{O}_{i}}\right) \cdot \frac{\partial X \mathrm{CH}_{4}}{\partial \mathrm{vmr}_{\mathrm{H}_{2} \mathrm{O}_{j}}}\left(T_{j}, \mathrm{vmr}_{\mathrm{H}_{2} \mathrm{O}_{j}}\right) \cdot\left\langle\delta \mathrm{vmr}_{\mathrm{H}_{2} \mathrm{O}_{i}} \cdot \delta \mathrm{vmrr}_{\mathrm{H}_{2} \mathrm{O}_{j}}\right\rangle}$.

Similarly, for random uncertainties in the temperature profile characterized by the covariances $\left\langle\delta T_{i} \cdot \delta T_{j}\right\rangle$, the resulting standard deviation of $\mathrm{XCH}_{4}$ can be calculated via:

$\operatorname{std}\left(\delta \mathrm{XCH}_{4_{T}}\right)$

$=\sqrt{\sum_{i, j} \frac{\partial X \mathrm{CH}_{4}}{\partial T_{i}}\left(T_{i}, \mathrm{vmr}_{\mathrm{H}_{2} \mathrm{O}_{i}}\right) \cdot \frac{\partial X \mathrm{CH}_{4}}{\partial T_{j}}\left(T_{j}, \operatorname{vmr}_{\mathrm{H}_{2} \mathrm{O}_{j}}\right) \cdot\left\langle\delta T_{i} \cdot \delta T_{j}\right\rangle}$.

Figures A1 and A2 show the result of applying Eqs. (A15) and (A14), respectively, using six representative climates (US standard atmosphere, tropical atmosphere, and summer and winter profiles at mid- and sub-arctic latitudes) as nominal atmospheric states $\left(T_{i}, \mathrm{vmr}_{\mathrm{H}_{2} \mathrm{O}_{i}}\right)$, for the methane trough at $6077 \mathrm{~cm}^{-1}$, i.e. option 2 of Table 1 . Similarly to an approach by Dufour and Breon (2003), and Breon et al. (2008), the uncertainties of the humidity and temperature profiles were estimated using globally averaged vertical error covariances calculated from ECMWF forecast difference data (Elias Holm, personal communication, 2011), shown on Figs. A3 and A4. Short-term forecast differences are a useful proxy to NWP analysis field uncertainties that are otherwise difficult to obtain. Since they also contain the forecast uncertainties, they can be considered as upper bounds to the uncertainties of the NWP analyses.

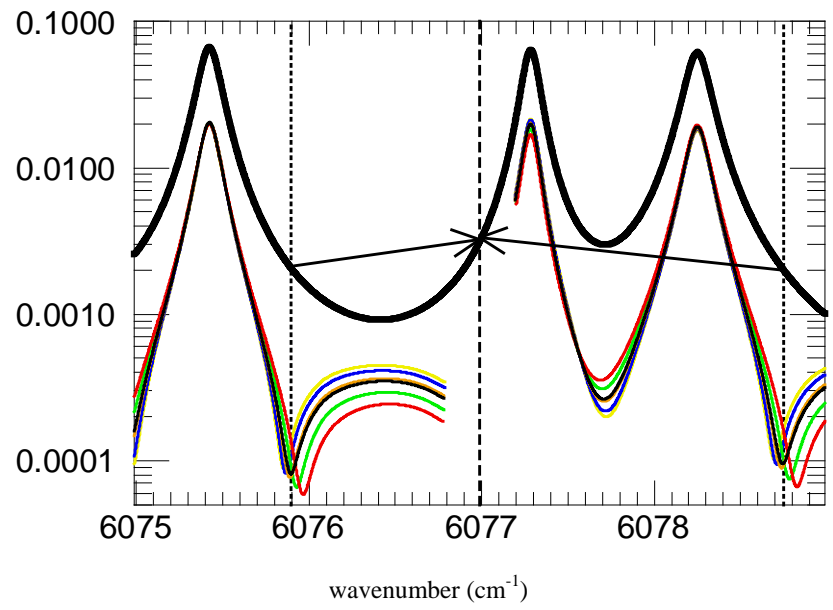

Fig. A2. Optical depth of water vapour absorption lines around the most favorable methane line multiplet at $1645.6 \mathrm{~nm}$ (black), with relative $X \mathrm{CH}_{4}$ uncertainty due to uncertainties in the water vapour profiles (colored according to Fig. A1), as function of offline wavenumber. The dotted vertical lines indicate the two closest off-line wavenumber candidates which minimize the uncertainty in the considered range of atmospheric states, thanks to the "water sensitivity cancellation" effect described in the text. The arrows point at the corresponding slightly positive water vapour differential optical depth for these online/offline pairs.

In Fig. A1, the relative $\mathrm{XCH}_{4}$ uncertainties due to atmospheric temperature uncertainties are plotted as a function of the on-line wavelength position assuming an "ideal" offline wavelength, i.e. close enough to the line multiplet and with zero methane optical depth. Additional uncertainties by absorption properties of the "real" off-line wavelength are of higher order and thus negligible. The temperature related $\mathrm{XCH}_{4}$ uncertainty in the centre of the trough is found to be very low with $\sim 0.3 \%$ o. Although the line-centre positions to the left and right of the trough in Fig. A1 have even lower temperature sensitivity, the weighting function figure of merit clearly shows that such a choice would lead to an unacceptable halving of the sensitivity in the lower troposphere, in addition to the fact that the one-way optical depth would be too far off the optimum value. The "minima" of temperature sensitivity near $6076.91,6076.96$ and $6077.02 \mathrm{~cm}^{-1}$, where the insensitivity to frequency shifts is lost, also have a weighting function and optical depth worse than in the centre of the trough. The situation is similar for all other options of Table 1 and can be summarized as follows: While not the lowest possible, the temperature sensitivity remains comfortably low in the trough centres, which simultaneously provide a suitable optical depth, better weighting functions than $\mathrm{CO}_{2}$ at $1.6 \mu \mathrm{m}$ (see Fig. 4), and insensitivity to frequency instabilities. Therefore, the trough centre is selected as nominal on-line wavelength for all options, and the ranges of measurement uncertainties due to temperature uncertainties (between best and worst case among the six representative atmospheric states) are indicated in Table 1. 

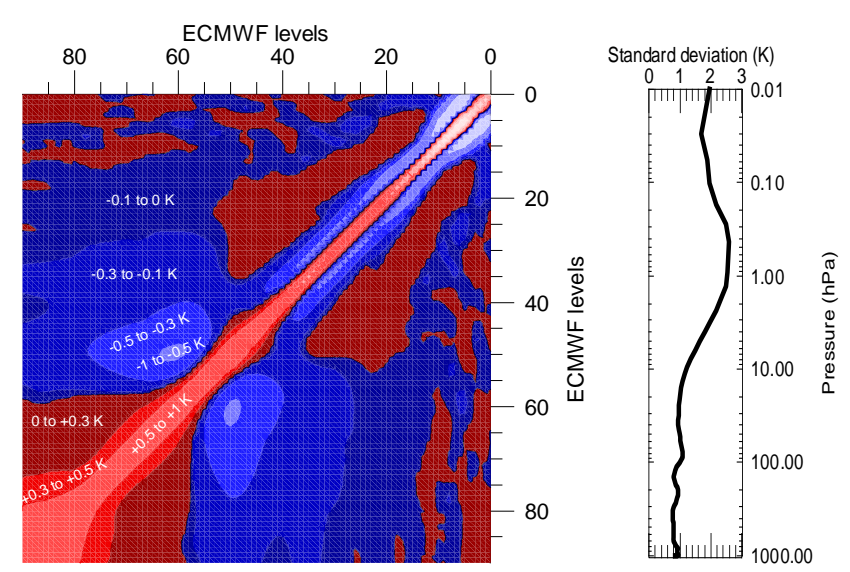

Fig. A3. Left: square root and sign of the $\left\langle\delta T_{i} \cdot \delta T_{j}\right\rangle$ terms used in Eq. (A15), as function of model level (level 0 corresponds to the lowest pressure, level 90 to the ground level). Blue indicates error anti-correlation (negative covariance), red correlation (positive covariance) between the two corresponding levels. Right: standard deviation of the uncertainties in the temperature profiles as function of pressure $(\mathrm{hPa})$, corresponding to the left array's diagonal.

Figure A2 shows the impact of humidity uncertainties as a function of the off-line wavelength position with the online wavelength fixed to its nominal value in the centre of the trough. At particular off-line positions the $\mathrm{XCH}_{4}$ uncertainty is minimized. The positions and values of the minima are slightly different for each atmospheric state but there is a range of off-line positions for which the uncertainty is lower than $10^{-4}$ or $0.1 \%$. This is due to the "water sensitivity cancellation" effect described by Caron and Durand (2009) which relies on the fact that the water vapour mixing ratio appears both in the DAOD $\mathrm{H}_{2} \mathrm{O}$ of the numerator in Eq. (A11) and in the weighting function in its denominator. More precisely, after developing the partial derivative of $\mathrm{XCH}_{4}$ with respect to the water vapour mixing ratio at pressure level $k$ from Eq. (A11), we obtain:

$$
\begin{aligned}
& \frac{\partial X \mathrm{XH}_{4}}{\partial \mathrm{vmr}_{\mathrm{H}_{2} \mathrm{O}}^{k}}=-\left(\frac{1}{\sum_{i} \mathrm{WF}_{i} \cdot \mathrm{d} p_{i}}\right)^{2} \\
& \quad\left(\left(\sum_{i} \mathrm{WF}_{i} \cdot \mathrm{d} p_{i}\right) \cdot \frac{\partial \mathrm{DAOD}_{\mathrm{H}_{2} \mathrm{O}}}{\partial \mathrm{vmr}_{\mathrm{H}_{2} \mathrm{O}}^{k}}+\mathrm{DAOD} \cdot \frac{\partial \mathrm{WF}_{k}}{\partial \mathrm{vmr}_{\mathrm{H}_{2} \mathrm{O}}^{k}} \cdot \mathrm{d} p_{k}\right),
\end{aligned}
$$

where the contributions of the aforementioned terms to the partial derivative appear as a sum of two terms in the second factor on the right-hand side. Since both the DAOD and the sum of the weighting function over all pressure levels are positive quantities, the signs of these terms are determined by the sign of the derivative of $\mathrm{DAOD}_{\mathrm{H}_{2} \mathrm{O}}$ with respect to $\mathrm{vmr}_{\mathrm{H}_{2} \mathrm{O}}^{k}$, and by the sign of the derivative of the methane $\mathrm{WF}_{k}$ with respect to $\mathrm{vmr}_{\mathrm{H}_{2} \mathrm{O}}^{k}$. While the latter is clearly negative due to the presence of $\mathrm{vmr}_{\mathrm{H}_{2} \mathrm{O}}^{k}$ in the denominator of Eq. (A5), Eq. (A10) shows that the former's

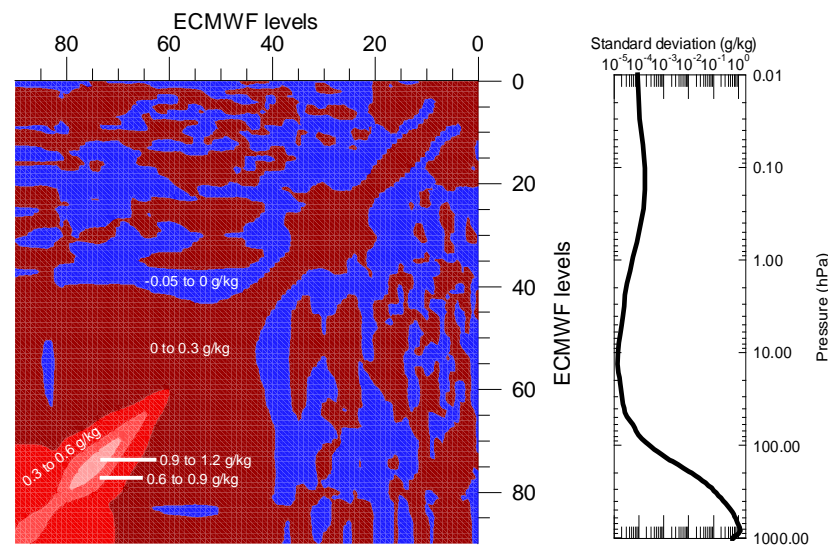

Fig. A4. As Fig. A3 but for the $\left\langle\delta v^{2} r_{\mathrm{H}_{2} \mathrm{O}_{i}} \cdot \delta \mathrm{vmr}_{\mathrm{H}_{2} \mathrm{O}_{j}}\right\rangle$ terms used in Eq. (A14), before conversion from specific humidity to water vapour volume mixing ratio.

sign and magnitude is driven by the differential absorption cross-section of water vapour for the selected on-/off-line wavelength pair. Provided that the on-line water vapour absorption cross-section is not too low, the off-line wavelength can be chosen in such a way as to give a positive differential absorption cross-section of water vapour with a magnitude such that both terms in the sum of Eq. (A16) cancel each other, with the interesting effect that the partial derivative of $\mathrm{XCH}_{4}$ with respect to $\mathrm{vmr}_{\mathrm{H}_{2} \mathrm{O}}^{k}$ becomes zero.

This condition cannot be fulfilled by a single off-line wavelength for all pressure levels $k$ simultaneously, a fortiori not for a range of atmospheric states, since the water vapour differential absorption cross section is pressure and temperature dependent. Figure A2 however demonstrates that it is possible to find off-line positions where the weighted sum of products of partial derivatives in Eq. (A14) is minimized. This is a generalization of the approach by Caron and Durand (2009) that assumed a uniform error on the water vapour profile and calculated the derivative of $\mathrm{XCH}_{4}$ with respect to this single error term. Figure A2 shows that such minima exist in the case of the line multiplet at $6077 \mathrm{~cm}^{-1}$, and that they indeed correspond to off-line positions that give rise to a small but non-zero positive water-vapour differential optical depth, as indicated by the arrows. Their location is compatible with the other constraints that govern the choice of the off-line position, i.e. close collocation to the online and relatively small methane optical depth as indicated in Fig. 3. Similar minima do not exist for the three other multiplets of Table 1 where the on-line water vapour optical depth is not large enough and the second term of the sum in Eq. (A16) consequently dominates. However, it is possible to find nearby offline positions for which the uncertainty due to water vapour remains generally slightly lower than the uncertainty due to temperature for the given error covariances. The ranges of measurement uncertainties due to water vapour uncertainties (between best and worst case among the 
six representative atmospheric states) for these off-line positions are indicated in Table 1. All sensitivities to temperature and water vapour were estimated using the error covariances described above and displayed in the Figs. A3 and A4.

Acknowledgements. We are grateful to Elias Holm (ECMWF) for the provision of global vertical temperature and humidity error covariances, to Clark Weaver for helpful comments, and to Pierre Flamant, the French MERLIN co-principal investigator, for fruitful discussions. Both referees, Robert Menzies and Syed Ismail, had very valuable comments.

Edited by: A. Lambert

\section{References}

Amediek, A., Fix, A., Ehret, G., Caron, J., and Durand, Y.: Airborne lidar reflectance measurements at $1.57 \mu \mathrm{m}$ in support of the A-SCOPE mission for atmospheric $\mathrm{CO}_{2}$, Atmos. Meas. Tech., 2, 755-772, doi:10.5194/amt-2-755-2009, 2009.

Bréon, F. M., Aben, I., Boesch, H., Bormann, N., Bruneau, D., Chevallier, F., Ehret, G., Engelen, R., Flamant, P., Gerbig, C., Heimann, M., Houweling, S., Lezeaux, F. O., Peylin, P., Prunet, P., Rayner, P., Rödenbeck, C., and Thepaut, J. N.: Observation Techniques and Mission Concepts for Analysis of the Global Carbon Cycle, Final Report, ESA Study, Contract No. 20839/07/NL/HE, 2008.

Bruneau, D., Gibert, F., Flamant, P. H., and Pelon, J.: Complementary study of differential absorption lidar optimization in direct and heterodyne detections, Appl. Optics, 45, 4898-4908, 2006.

Caron, J. and Durand, Y.: Operating wavelengths optimization for a spaceborne lidar measuring atmospheric $\mathrm{CO}_{2}$, Appl. Optics, 48, 5413-5422, 2009.

Davy, B., Pecher, I., Wood, R., Carter, L., and Gohl, K.: Gas escape features off New Zealand: Evidence of massive release of methane from hydrates, Geophys. Res. Lett., 37, L21309, doi:10.1029/2010GL045184, 2010.

Dee, D. P., Uppala, S. M., Simmons, A. J., Berrisford, P., Poli, P., Kobayashi, S., Andrae, U., Balmaseda, M. A., Balsamo, G., Bauer, P., Bechtold, P., Beljaars, A. C. M., van de Berg, L., Bidlot, J., Bormann, N., Delsol, C., Dragani, R., Fuentes, M., Geer, A. J., Haimberger, L., Healy, S. B., Hersbach, H., Holm, E. V., Isaksen, L., Kallberg, P., Koehler, M., Matricardi, M., McNally, A. P., Monge-Sanz, B. M., Morcrette, J.-J., Park, B.-K., Peubey, C., de Rosnay, P., Tavolato, C., Thepaut, J.-N., and Vitart, F.: The ERA-Interim reanalysis: configuration and performance of the data assimilation system, Q. J. Roy. Meteorol. Soc., 137, 553597, doi:10.1002/qj.828, 2011.

Dufour, E. and Bréon, F.-M.: Spaceborne estimate of atmospheric $\mathrm{CO}_{2}$ column by use of the differential absorption method: error analysis, Appl. Optics, 42, 3595-3609, 2003.

Ehret, G. and Kiemle, C.: Requirements Definition for Future DIAL Instruments, Final Report, ESA Study CR(P)-4513, Contract 10880/03/NL/FF, 2005.

Ehret, G., Kiemle, C., Wirth, M., Amediek, A., Fix, A., and Houweling, S.: Space-borne remote sensing of $\mathrm{CO}_{2}, \mathrm{CH}_{4}$, and $\mathrm{N}_{2} \mathrm{O}$ by integrated path differential absorption lidar: a sensitivity analysis, Appl. Phys. B, 90, 593-608, doi:10.1007/s00340-0072892-3, 2008.
Ehret, G., Flamant, P., Amediek, A., Ciais, P., Gibert, F., Fix, A., Kiemle, C., Quatrevalet, M., and Wirth, M.: The French-German Climate Monitoring Initiative on Global Observations of Atmospheric Methane, Proc. 25th Int. Laser Radar Conf., St. Petersburg, Russia, July 2010.

Forster, P., Ramaswamy, V., Artaxo, P., Berntsen, T., Betts, R., Fahey, D. W., Haywood, J., Lean, J., Lowe, D. C., Myhre, G., Nganga, J., Prinn, R., Raga, G., Schulz, M., and Van Dorland, R.: Changes in Atmospheric Constituents and in Radiative Forcing, in: Climate Change 2007: The Physical Science Basis. Contribution of Working Group I to the Fourth Assessment Report of the Intergovernmental Panel on Climate Change, edited by: Solomon, S., Qin, D., Manning, M., Chen, Z., Marquis, M., Averyt, K.B., Tignor, M., and Miller, H. L., Cambridge University Press, Cambridge, UK and New York, NY, USA, 2007.

Frankenberg, C., Warneke, T., Butz, A., Aben, I., Hase, F., Spietz, P., and Brown, L. R.: Pressure broadening in the $2 v_{3}$ band of methane and its implication on atmospheric retrievals, Atmos. Chem. Phys., 8, 5061-5075, doi:10.5194/acp-8-5061-2008, 2008.

Gerbig, C., Dolman, A. J., and Heimann, M.: On observational and modelling strategies targeted at regional carbon exchange over continents, Biogeosciences, 6, 1949-1959, doi:10.5194/bg6-1949-2009, 2009.

Heimann, M.: How Stable Is the Methane Cycle?, Science, 327, 1211-1212, 2010.

Hungershoefer, K., Breon, F.-M., Peylin, P., Chevallier, F., Rayner, P., Klonecki, A., Houweling, S., and Marshall, J.: Evaluation of various observing systems for the global monitoring of $\mathrm{CO}_{2}$ surface fluxes, Atmos. Chem. Phys., 10, 10503-10520, doi:10.5194/acp-10-10503-2010, 2010.

Ingmann, P., Bensi, P., and Durand, Y.: Candidate Earth Explorer Core Missions - Reports for Assessment: A-SCOPE - Advanced Space Carbon and climate Observation of Planet Earth, ESA SP1313/1, ISBN 978-92-9221-406-7, ISSN 0379-6566, 2008.

Ismail, S. and Browell, E. V.: Airborne and spaceborne lidar measurements of water vapor profiles: a sensitivity analysis, Appl. Opticsc, 28, 3603-3614, 1989.

Kaminski, T., Scholze, M., and Houweling, S.: Quantifying the benefit of A-SCOPE data for reducing uncertainties in terrestrial carbon fluxes in CCDAS, Tellus B, 62, 784-796, doi:10.1111/j.1600-0889.2010.00483.x, 2010.

Kawa, S. R., Mao, J., Abshire, J. B., Collatz, G. J., Sun, X., Weaver, C. J.: Simulation studies for a space-based $\mathrm{CO}_{2}$ lidar mission, Tellus B, 62, 759-769, doi:10.1111/j.1600-0889.2010.00486.x, 2010.

Mayer, B. and Kylling, A.: Technical note: The libRadtran software package for radiative transfer calculations - description and examples of use, Atmos. Chem. Phys., 5, 1855-1877, doi:10.5194/acp-5-1855-2005, 2005.

Menzies, R. T., Tratt, D. M., Spinhirne, J. D., and Hlavka, D. L.: Aerosol layers over the Pacific Ocean: Vertical distributions and optical properties as observed by multiwavelength airborne lidars, J. Geophys. Res., 107, 4292, doi:10.1029/2001JD001196, 2002.

Milkov, A. V.: Global estimates of hydrate-bound gas in marine sediments: How much is really out there?, Earth Sci. Rev. 66, 183-197, doi:10.1016/j.earscirev.2003.11.002, 2004. 
Morino, I., Uchino, O., Inoue, M., Yoshida, Y., Yokota, T., Wennberg, P. O., Toon, G. C., Wunch, D., Roehl, C. M., Notholt, J., Warneke, T., Messerschmidt, J., Griffith, D. W. T., Deutscher, N. M., Sherlock, V., Connor, B., Robinson, J., Sussmann, R., and Rettinger, M.: Preliminary validation of column-averaged volume mixing ratios of carbon dioxide and methane retrieved from GOSAT short-wavelength infrared spectra, Atmos. Meas. Tech., 4, 1061-1076, doi:10.5194/amt-4-1061-2011, 2011.

Petersen, A. K., Warneke, T., Frankenberg, C., Bergamaschi, P., Gerbig, C., Notholt, J., Buchwitz, M., Schneising, O., and Schrems, O.: First ground-based FTIR observations of methane in the inner tropics over several years, Atmos. Chem. Phys., 10, 7231-7239, doi:10.5194/acp-10-7231-2010, 2010.

Rothman, L. S., Gordon, I. E., Barbe, A., Benner, D. C., Bernath, P. F., Birk, M., Boudon, V., Brown, L. R., Campargue, A., Champion, J.-P., Chance, K., Coudert, L. H., Dana, V., Devi, V. M., Fally, S., Flaud, J.-M., Gamache, R. R., Goldman, A., Jacquemart, D., Kleiner, I., Lacome, N., Lafferty, W. J., Mandin, J.Y., Massie, S. T., Mikhailenko, S. N., Miller, C. E., MoazzenAhmadi, N., Naumenko, O., Nikitin, A. V., Orphal, J., Perevalov, V. I., Perrin, A., Predoi-Cross, A., Rinsland, C. P., Rotger, M., Simecková, M., Smith, M. A. H., Sung, K., Tashkun, S. A., Tennyson, J., Toth, R. A., Vandaele, A. C., and Vander Auwera, J.: The HITRAN 2008 molecular spectroscopic database, J. Quant. Spectrosc. Ra., 110, 533-572, doi:10.1016/j.jqsrt.2009.02.013, 2009.
Schneising, O., Buchwitz, M., Reuter, M., Heymann, J., Bovensmann, H., and Burrows, J. P.: Long-term analysis of carbon dioxide and methane column-averaged mole fractions retrieved from SCIAMACHY, Atmos. Chem. Phys., 11, 28632880, doi:10.5194/acp-11-2863-2011, 2011.

Vaughan, J. M., Brown, D. W., Nash, C., Alejandro, S. B., and Koenig, G. G.: Atlantic atmospheric aerosols studies 2. Compendium of airborne backscatter measurements at $10.6 \mu \mathrm{m}, \mathrm{J}$. Geophys. Res., 100, 1043-1065, 1995.

Villani, M. G., Bergamaschi, P., Krol, M., Meirink, J. F., and Dentener, F.: Inverse modeling of European $\mathrm{CH}_{4}$ emissions: sensitivity to the observational network, Atmos. Chem. Phys., 10, 1249-1267, doi:10.5194/acp-10-1249-2010, 2010. 